Federal Reserve Bank of Minneapolis

Research Department Staff Report 484

June 2013

\title{
Measuring the Financial Soundness of U.S. Firms, 1926-2012*
}

\author{
Andrew G. Atkeson \\ University of California Los Angeles, \\ NBER, and Federal Reserve Bank of Minneapolis
}

Andrea L. Eisfeldt

University of California Los Angeles

Pierre-Olivier Weill

University of California Los Angeles

\begin{abstract}
Building on the Merton (1974) and Leland (1994) structural models of credit risk, we develop a simple, transparent, and robust method for measuring the financial soundness of individual firms using data on their equity volatility. We use this method to retrace quantitatively the history of firms' financial soundness during U.S. business cycles over most of the last century. We highlight three main findings. First, the three worst recessions between 1926 and 2012 coincided with insolvency crises, but other recessions did not. Second, fluctuations in asset volatility appear to drive variation in firms' financial soundness. Finally, the financial soundness of financial firms largely resembles that of nonfinancial firms.
\end{abstract}

Keywords: Volatility, Distance to Default, Credit Risk Modeling, Financial Frictions and Business Cycles

JEL Classification: E32, E44, G01, G32

*Atkeson: andy@atkeson.net; Eisfeldt: andrea.eisfeldt@anderson.ucla.edu; Weill: poweill@econ.ucla.edu. Robert Kurtzman, David Zeke, and Leo Li provided expert research assistance. We thank Tyler Muir, Bryan Kelly, and seminar participants at UCLA Anderson, the Federal Reserve Bank of Minneapolis, the Society for Economic Dynamics, Science Po Paris, UCL, Princeton, the Wharton liquidity conference, Berkeley Haas, UCSB, Claremont McKenna, Carnegie Mellon, Chicago Booth, Columbia GSB, MIT, and the Banque de France-Deutsche Bundesbank Conference on Macroeconomics and Finance Conference for fruitful discussion and comments. All errors are ours. The views expressed herein are those of the authors and not necessarily those of the Federal Reserve Bank of Minneapolis or the Federal Reserve System. 


\section{Introduction}

A large literature in macroeconomics argues that financial frictions impair the flow of resources to and across firms and play a key role in amplifying and propagating business cycle shocks. Papers in this literature include Bernanke and Gertler (1989), Carlstrom and Fuerst (1997), Kiyotaki and Moore (1997), Bernanke, Gertler, and Gilchrist (1999), Cooley and Quadrini (2001), Cooley, Marimon, and Quadrini (2004), and many others. One central theme in this literature is that the distribution of financial soundness across firms in the economy at any point in time is an aggregate state variable that has consequences for the response of the macroeconomy to a variety of aggregate shocks. In particular, in these theories, negative macroeconomic shocks are greatly amplified and propagated when they simultaneously deteriorate the distribution of financial soundness across firms.

Motivated by the literature cited above, in this paper we develop a simple, transparent, theoretically grounded, and broadly applicable empirical procedure for measuring the distribution of financial soundness across a wide cross section of firms in the economy and over a long historical time period. We propose to measure an individual firm's financial soundness at a point in time by Distance to Insolvency, or DI: its leverage adjusted for the volatility of innovations to the market valuation of its underlying assets (also called the firm's business risk). Put differently, DI is a measure of the adequacy of the firm's equity cushion relative to the riskiness of the firm as a whole.

We first offer a theoretical analysis of DI in the context of the structural credit risk model of Leland (1994). Our main result is that a firm's DI is bounded above by the inverse of its instantaneous equity volatility. Moreover, this bound is tight if the firm's creditors are alert and aggressive in quickly forcing the firm into bankruptcy when it becomes insolvent. Because this result is based only on elementary properties of the value of the firm's equity as a function of the value of the firm's assets in the model, we conjecture that it should generalize to a wider class of structural credit risk models. Based on these findings, in our empirical work we approximate a firm's DI with the inverse of its equity volatility.

Next, we validate our equity-based measure of DI by showing empirically that it is highly correlated with leading alternative empirical measures of firms' financial soundness, whenever data are available for these alternative measures. The alternative measures that we consider include credit ratings, option-adjusted bond spreads, credit default swap rates, aggregate bond default rates, and the measure of firms' Distance to Default based on the structural credit risk model of Merton (1974), which is commonly used in forecasting individual firms' bond default and bankruptcy rates (see, for example, Duffie, 2011; Sun, 
Munves, and Hamilton, 2012). These correlations are strong and relatively stable both in the cross section at a point in time and across time, including even the turbulent financial crisis of 2008.

The primary advantage of our measure of DI, relative to leading alternatives, is that it requires only data on firms' equity volatility and hence can be computed for a very broad set of firms over a very long historical time period. We capitalize on this simplicity of our measure to compute the cross section distribution of DI for each month from 1926 through 2012 for all publicly traded U.S. firms in the database maintained by the Center for Research in Security Prices (CRSP). We find that over the entire time period, the distribution of measured DI across firms is approximately lognormal, so it can be summarized well in a low-dimensional manner by two of its moments. ${ }^{1}$ Moreover, we find that fluctuations in the median (or mean) of this lognormal distribution account for most of the movements in the entire distribution - the fluctuations in the crosssectional standard deviation of these lognormal distributions are relatively small. Thus, the median measured DI gives us a new and parsimonious picture of the evolution of the entire distribution of financial soundness across U.S. firms at a high frequency, over a time frame that includes both the Great Depression and a large number of subsequent business cycles.

We find that over the 1926-2012 time period a number of episodes occurred in which the entire distribution of measured DI across publicly traded firms in the United States deteriorated sharply. We term these episodes insolvency crises. In particular, we define insolvency crises as months in which the median measured DI in that month's cross section of firms drops to a level normally associated with extreme financial distress, and the 95th percentile of measured DI drops to a level normally associated with junk credit ratings or worse.

We then use our measure of DI to address three empirical questions regarding the relationship between insolvency crises and U.S. business cycles since 1926. First, are U.S. recessions since 1926 systematically associated with insolvency crises? Second, are insolvency crises driven by changes in firms' leverage or instead by changes in the volatility in the valuation of firms' underlying assets? Third, are financial firms different from nonfinancial firms in terms of the behavior of their distance to insolvency both before and during insolvency crises?

With regard to the first question, we find that the largest recessions in our sample, namely 1932-1933, 1937, and 2008, are closely associated with insolvency crises. However,

\footnotetext{
${ }^{1}$ We are grateful to Bryan Kelly for pointing this out to us. See Kelly, Lustig, and Van Nieuwerburgh (2013b) for a study of the evolution of the cross section distribution of volatility.
} 
we do not find significant insolvency crises in other recessions outside of these three. This includes even the deep recessions of the late 1970s and early 1980s. These findings are not sensitive to the cutoffs used to define insolvency crises - the insolvency crises of 1932-33, 1937, and 2008 are quite distinctive events in the data. These findings are consistent with the hypothesis that financial frictions played a major role in three of the largest recessions in U.S. history. At the same time, these findings cast doubt on the importance of financial frictions for U.S. postwar recessions outside of the most recent one. ${ }^{2}$

The second question is motivated by the macroeconomic literature emphasizing that the distribution of leverage across firms is likely to be a key state variable for determining the effects of financial frictions on the aggregate economy. A significant literature points to the buildup of leverage across firms as a key precursor to the start of a financial crisis (see, for example, Kindleberger and Aliber, 2005, and Reinhart and Rogoff, 2009). The impact of changes in asset volatility or business risk on firms' financial soundness and financial frictions, on the other hand, has been examined more closely only recently, for example, by Bloom (2009), Christiano, Motto, and Rostagno (2010), Gilchrist, Sim, and Zakrajsek (2010), Rampini and Viswanathan (2010), Arellano, Bai, and Kehoe (2011), and others. ${ }^{3}$ For the time period 1972-2012, we can use accounting data from COMPUSTAT in order to measure separately the leverage and asset volatility components of DI. This allows us to examine the role of changes in firms' leverage versus changes in firms' asset volatilities in accounting for the changes in the distribution of firms' measured DI over this time period, in particular during the insolvency crisis of 2008.

Contrary to many theories of financial crises, we find that the deterioration of firms' DI during the insolvency crisis of 2008 appears to be mainly a result of an increase in asset volatility for all firms. The contribution of the increase in leverage, induced by either "excessive borrowing" or a fall in asset values in this insolvency crisis, was relatively small. In fact, over the entire period for which we have the COMPUSTAT accounting data needed to compute firms' leverage, we find that changes over time in the distribution of DI across firms are mainly a result of changes in the volatility of firms' underlying assets rather than of changes in firms' leverage. ${ }^{4}$

We find it striking, moreover, that our measure of the distribution of financial soundness across firms both financial and nonfinancial rose to historically high levels of sound-

\footnotetext{
${ }^{2}$ See Giesecke, Longstaff, Schaefer, and Strebulaev (2011) for a related quantitative finding based on bond default rates.

${ }^{3}$ Recent related empirical work by Jurado, Ludvigson, and Ng (2013) provides a measure of uncertainty by measuring the volatility of the unforecastable component of macroeconomic time series.

${ }^{4}$ Related findings appear in the contemporaneous work by Choi and Richardson (2013) on the decomposition of levered equity returns with stochastic volatility. Their findings corroborate the greater relative contribution to equity volatility of asset volatility relative to leverage.
} 
ness in advance of the crisis of 2008, despite the increase in leverage that occurred over this period. A similarly striking finding is that the distribution of financial soundness across firms deteriorates over the periods 1926-1929 and 1995-2000, despite the large increases in stock prices experienced over these time periods. Taken together, these observations suggest that measures of leverage traditionally used in macroeconomic analysis behave very differently over time from measures of financial soundness, such as ours, that adjust leverage for business risk. On the basis of these findings, we argue that in order to understand insolvency crises, one must account for changes in firms' asset volatility over and above changes in firms' leverage.

The macroeconomic literature cited above highlights the role of financial frictions facing all firms in shaping business cycles. Another large literature in macroeconomics makes the case that frictions facing financial intermediaries play perhaps an even larger role in shaping the evolution of the macroeconomy. According to this literature, recessions can be caused by a deterioration in the financial soundness of financial intermediaries alone, due to their central role in reallocating resources in the economy. Important papers in this literature include Bernanke (1983) and recent surveys of theory by Gertler and Kiyotaki (2010) and of empirical experience with financial crises by Reinhart and Rogoff (2009).

One of the main virtues of our proposed method for measuring the financial soundness of firms is that it can easily be applied to financial as well as nonfinancial firms even though the type and reporting of leverage in financial statements vary considerably across the two types of firms. In our empirical work, we apply our method to measure the distribution of financial soundness for publicly traded financial firms from 1926 through 2012. This allows us to address our third question: is the evolution of the distribution of financial soundness significantly different for financial firms than for other firms during and in advance of insolvency crises?

We find that the evolution of the distribution of financial soundness for publicly traded financial firms closely resembles that of nonfinancial firms. If one considers all financial firms, the median measured DI for these firms is roughly equal to that of all nonfinancial firms in the first half of the sample, and exceeds the median measured DI for all nonfinancial firms in the second half of the sample. In order to address the potential "systemic importance" of large financial institutions, we focus on the second half of our sample, in which the number of financial firms is large enough for them to be compared meaningfuly to nonfinancial firms. We find that from 1962 to 2012, the evolution of the median measured DI for the top 50 financial firms in terms of equity market capitalization is virtually identical to that of the top 50 nonfinancial firms. Finally, if one instead focuses on a set 
of large financial firms identified ex post as systemically important after the 2008 financial crisis, we find that the evolution of the median measured DI for these large financial firms is virtually identical to that of the 50 largest nonfinancial firms over the period July 1962--July 2007. However, since the onset of the crisis in August 2007 until 2012, median measured DI for these large financial firms has been significantly worse. Clearly, it is too early to draw strong conclusions from the evidence presented here regarding the question of whether some subset of systemically important financial firms plays a special role in insolvency crises - our findings simply show correlations. Despite this, we find these results striking for two reasons.

First, there has been a widespread discussion that large financial firms' have dramatically changed their leverage and risk-taking behavior in response to changes in financial regulation, macroeconomic volatility, and financial innovations over the past several decades. Through the lens of measured DI, however, we see no evidence that changes in these factors led to changes in market participants' perceptions of the financial soundness of large financial firms relative to nonfinancial firms. It appears that market participants viewed whatever changes in large financial firms' leverage that may have occurred over this time period as corresponding to offsetting changes in these firms' business risks that left these firms with effective equity cushions remarkably similar to those of their large nonfinancial peers.

Second, consistent with many accounts of the current crisis, we do find that starting in August of 2007, institutions recently identified as systemically important ex post experienced a disproportionate deterioration in their financial soundness and have exhibited a slower recovery of their distance to insolvency relative to their large nonfinancial peers. Our findings are thus also consistent with arguments in Diamond and Rajan (2011) and Admati, DeMarzo, Hellwig, and Pfleiderer (2012) that increased regulatory efforts have not overcome the problems of debt overhang and moral hazard facing those remaining financial institutions that have been labeled as systemically important.

The remainder of this paper is organized as follows. In section 2, we describe the theory underlying our measurement procedure. In section 3 we compare the empirical performance of our measure of firms' distance to insolvency to alternative measures of firms' financial soundness. We then turn to an analysis of the characteristics of the distribution of distance to insolvency across firms as our aggregate state variable of interest. In section 4 we present our empirical results regarding our three questions on the relationship between insolvency crises and business cycles. We conclude in section 5 with a discussion of the implications of these findings for business cycle research. 


\section{The Theory Underlying Our Measurement}

Our empirical work has its theoretical foundations in the structural models of firms' credit risk pioneered by Merton (1974) and Leland (1994). In those models, a key state variable summarizing a firm's financial soundness is Distance to Insolvency, or DI: a measure of the firm's leverage adjusted by the volatility of innovations to the market valuation of its underlying assets. DI is a key state variable both in a statistical sense - it summarizes the probability that the firm will become insolvent in the future ${ }^{5}$ - and in an economic sense because it summarizes the distortions to equity holders' incentives that potentially arise when the firm becomes financially distressed. ${ }^{6}$

In this section we use a straightforward extension of Leland's (1994) structural model of credit risk in order to derive two approximation results that dramatically simplify measurement relative to what has been done in the academic literature and in commercial applications. We show that one can approximate a firm's DI simply with the inverse of its instantaneous equity volatility. Specifically, we show that in the Leland's model of credit risk, at any point in time, inverse equity volatility is an upper bound on the firm's $D I$. Second, if the firm's creditors are aggressive in forcing the equity holders to file for bankruptcy as soon as the firm is insolvent, then this upper bound is tight. ${ }^{7}$ We argue that because these findings rely on just a few elementary properties of the value of equity, they are likely to hold in a broad class of models.

\footnotetext{
${ }^{5}$ A large literature uses a related measure of firms' leverage adjusted for asset volatility computed from the Merton model to forecast firms' bond default and bankruptcy rates in a reduced-form manner. Duffie (2011) clearly describes one way in which this procedure can be implemented. Moody's Analytics (a subsidiary of the credit rating agency) has sold the results from a related model under the brand name Expected Default Frequency, or EDF, for over a decade. The specification of their model and its empirical implementation are described in Sun, Munves, and Hamilton (2012).

${ }^{6}$ To generate real costs of financial distress, these models rely on some violation of the Modigliani and Miller theorem (Modigliani and Miller, 1958). Myers (1977) is an early contribution characterizing the cost of debt financing arising from suboptimal investment. Townsend (1979) studies optimal financing under asymmetric information and shows that debt financing minimizes monitoring costs. Diamond and He (forthcoming) shows that investment distortions due to debt overhang vary with debt maturity, and they derive the optimal debt maturity structure. Villamil (2008) presents a survey of some of the important theoretical work that derives violations of Modigliani and Miller from the underlying constraints on contracting and information. Recent work by Almeida and Philippon (2007), Chen (2010), and Bhamra, Kuehn, and Strebulaev (2010) emphasizes the time-varying nature of the costs of financial distress.

${ }^{7}$ Black and Cox (1976) pioneered the study of structural models of credit risk in which creditors add bond provisions to force equity to exercise their right to limited liability when the firm becomes insolvent. Longstaff and Schwartz (1995) build on the Black and Cox model to incorporate both default and interest rate risk.
} 


\subsection{Distance to Insolvency: Definition}

To define terms, we make use of the following notation. On the left-hand side of its balance sheet, the firm has assets that yield at time $t \geq 0$ a stochastic cash flow denoted by $y_{t}$. Let $V_{A t}$ be the market value of the assets' future cash flows, measured using state-contingent prices. On the right-hand side of its balance sheet, the firm has liabilities, that we model as a deterministic sequence of cash flows $\left\{c_{t}, t \geq 0\right\}$ that the equity holders of the firm are contractually obligated to pay if they should wish to continue as owners of the firm. Let $V_{B t}$ be the market value of the liabilities' future cash flows, valued as if they were default free. Of course, since the firm may default on its liabilities, $V_{B t}$ is larger than the market value of the firm's debt. We say that a firm is solvent if its underlying assets are worth more than the promised value of its liabilities, $V_{A t} \geq V_{B t}$, and insolvent otherwise. Let the asset volatility, $\sigma_{A t}$, be the (instantaneous) annualized percentage standard deviation of innovations to $V_{A t}$, representing the business risk that the firm faces. Let the leverage be the percentage gap between the value of the firm's underlying assets and the firm's

liabilities, $\frac{V_{A t}-V_{B t}}{V_{A t}}$. A firm's Distance to Insolcency is defined as the ratio of our measure of leverage to our measure of asset volatility, both dated at a point in time $t$ :

$$
D I_{t} \equiv\left(\frac{V_{A t}-V_{B t}}{V_{A t}}\right) \frac{1}{\sigma_{A t}} .
$$

This ratio corresponds to the drop in asset value that would render the firm insolvent, measured in units of the firm's asset standard deviation.

We illustrate these concepts graphically in Figure 1. The solid blue line in the figure denotes the evolution of the value of the firm's assets, $V_{A t}$, over time. The solid blue line ends at the current time $t$. The solid red line denotes the value of the firm's promised liabilities $V_{B t}$. The black arrow denotes the distance between $V_{A t}$ and $V_{B t}$ at time $t$. The dashed blue lines denote standard error bands around the evolution of $V_{A t+s}$ going forward at different time horizons $s>0$. The likelihood that the firm becomes insolvent in the near term depends on both the distance between $V_{A t}$ and $V_{B t}$, measured here in percentage terms by the firm's leverage, and the volatility in percentage terms of innovations to the value of the firm's assets. We combine these two factors into DI, which serves as simple one-dimensional index of the firm's financial soundness.

\subsection{Distance to Insolvency: Measurement}

Calculating a firm's DI is challenging in practice because it requires one to measure separately the market value and volatility of a firm's underlying assets, $V_{A t}$ and $\sigma_{A t}$, and 
the value of its liabilities, $V_{B t}$. The former are not directly observable, and the latter is subject to deficiencies and inconsistencies in accounting measures of firms' liabilities across countries, time, and industries.

One approach to this measurement problem, pioneered by Merton (1974) and Leland (1994), is to use a specific structural model of the cash flows from the firm's assets and on the firm's liabilities, together with assumptions about the interest rates and risk prices used to discount those cash flows. Equipped with such a model, one can derive formulas for the value of the firm's equity at $t$, denoted by $V_{E t}$, and the standard deviation of the innovations to the logarithm of $V_{E t}$, denoted by $\sigma_{E t}$, as functions of the asset value and volatility and the firm's liabilities, $V_{A t}, \sigma_{A}$, and $V_{B t}$. Given data on the firm's equity value, equity volatility, and liabilities, one can then invert these formulas to uncover the unobserved asset value $V_{A t}$ and asset volatility $\sigma_{A t}$. Duffie (2011) clearly describes one way in which this procedure can be implemented using the Merton model.

Our theoretical results below show that one can approximate DI in a simple and robust way without relying on noisy accounting information, using only equity volatility data.

The Leland Model. Let interest rates and the market price of risk be constant. On the left-hand side of the firm's balance sheet, the cash flows derived from the firm's underlying assets (lines of business) follow a geometric Brownian motion with constant volatility. In this case, the market value of the firm's asset, $V_{A t}$, also follows a geometric Brownian motion with constant volatility $\sigma_{A}$. In particular, fluctuations in $V_{A t}$ are driven entirely by fluctuations in the firm's projected cash flows. On the right-hand side of its balance sheet, the firm has liabilities given by a perpetual constant flow of payments $c>0$. Hence, the present value of these payments is constant and equal to $V_{B}=c / r$, where $r>0$ denotes the interest rate.

Equity holders have limited liability, in that they can choose to stop making the contractual liability payments, in which case they default and assets are transferred to creditors. Creditors are protected by covenants, allowing them to force equity holders into default if the value $V_{A t}$ of the assets falls below some exogenously given threshold, which we assume is lower than $V_{B}$. Using standard arguments, one can show that, when the value of assets falls below some endogenous threshold $V_{A}^{\star} \leq V_{B}$, either equity holders exercise their right to default or creditors exercise their protective covenants. The value of equity can be written as $V_{E t}=w\left(V_{A t}\right)$, for some continuous function $w\left(V_{A}\right)$ with key properties illustrated in Figure 2.

Lemma 1. In the Leland (1994) structural model, the value of equity, $w\left(V_{A}\right)$, is greater than $\max \left\{0, V_{A}-V_{B}\right\}$, nondecreasing, convex, and satisfies $w^{\prime}\left(V_{A}\right) \leq 1$ as well as $w\left(V_{A}^{\star}\right)=$ 
0.

The lower bound, $\max \left\{0, V_{A}-V_{B}\right\}$, follows from the limited liability assumption: the value of equity has to be greater than zero, and it also has to be greater than $V_{A}-V_{B}$, its value under unlimited liability. Moreover, in line with the original insights from Merton (1974), the value of equity inherits the standard convexity properties of call options. ${ }^{8}$ Note in particular that $w^{\prime}\left(V_{A}\right) \leq 1$, which follows from the fact that the option value of limited liability falls as the value of the firm's assets rises. Finally, the value of equity must be zero at the default point, $V_{A}^{\star}$.

Armed with these basic properties for the value of equity, we develop our two approximation results that relate distance to insolvency and leverage adjusted for asset volatility. We show each result in turn.

Proposition 1. In a Leland (1994) structural model, Distance to Insolvency bounded above by the inverse of equity volatility:

$$
D I_{t}=\left(\frac{V_{A t}-V_{B t}}{V_{A t}}\right) \frac{1}{\sigma_{A t}} \leq \frac{1}{\sigma_{E t}} .
$$

Proof. To prove this result, note first that, by Ito's formula, the volatility of equity solves:

$$
\sigma_{E t}=\frac{w^{\prime}\left(V_{A t}\right)}{w\left(V_{A t}\right)} \sigma_{A} V_{A t} \Longrightarrow \frac{1}{\sigma_{E t}}=\frac{w\left(V_{A t}\right)}{w^{\prime}\left(V_{A t}\right)} \frac{1}{\sigma_{A} V_{A t}} .
$$

By Lemma 1 we have that $w\left(V_{A t}\right) \geq V_{A t}-V_{B t}$, and $w^{\prime}\left(V_{A t}\right) \leq 1$, and the results follow.

Next, consider the question of whether this upper bound on a firm's DI is tight. To do this, recall that $V_{A}^{\star}$ is the threshold asset value at which equity exercises its option to default: it gives up control of the firm's assets in exchange for abandoning the firm's liabilities. We use $V_{A t}^{\star}$ to define the concept of Distance to Default, or DD, in the Leland model as

$$
D D_{t}=\left(\frac{V_{A t}-V_{A t}^{\star}}{V_{A t}}\right) \frac{1}{\sigma_{A}} .
$$

Note that default is distinct from insolvency in our theory and that quite generally a firm's DD exceeds its DI. This is because equity may not walk away immediately from an insolvent firm, but will not choose default if the firm is solvent. With this definition we have our second proposition.

\footnotetext{
${ }^{8}$ The Merton model differs from the Leland model only in the assumption that the cash flows on liabilities are simply a single cash flow required at a specific date $T$ in the future. This lemma also applies to the value of equity in the Merton model at dates $t<T$ with the change that $V_{A}^{\star}=0$.
} 
Proposition 2. In a Leland (1994) structural model, the inverse of a firm's equity volatility lies between its Distance to Insolvency and its Distance to Default:

$$
D I_{t} \leq \frac{1}{\sigma_{E t}} \leq D D_{t}
$$

Proof. This proposition follows from the convexity of the value of the firm's equity as a function of the value of the firm's assets at each time $t$ and because $w\left(V_{A}^{\star}\right)=0$.

We illustrate the proof of these two propositions in Figure 2. At time $t$, the value of the firm's equity as a function of the value of its assets is a convex function with slope less than or equal to one that lies above the horizontal axis (exceeds zero) and the line $V_{A t}-V_{B}$ giving the value of the firm's equity under unlimited liability. The value of the firm's equity hits the horizontal axis at the default point $V_{A t}^{\star}$. Define $X_{t}$ to be the point at which the tangent line to the value of equity $V_{E t}$ at the current asset value $V_{A t}$ hits the $x$-axis. All these lines and points are drawn in this figure.

By the convexity of $w\left(V_{A}\right)$, we have $V_{A t}^{\star} \leq X_{t} \leq V_{B t}$. Simple algebra then delivers that

$$
\frac{1}{\sigma_{E t}}=\left(\frac{V_{A t}-X_{t}}{V_{A t}}\right) \frac{1}{\sigma_{A}}
$$

which proves the result.

With these two results, we have that the inverse of a firm's equity volatility, $1 / \sigma_{E}$, is an accurate measure of Distance to Insolvency if the Distance to Insolvency and the Distance to Default are close to one another. That is, the bound is tight if creditors quickly force insolvent firms into default. Therefore, as an empirical matter, the economics of creditors' incentives to force a firm that is insolvent into bankruptcy as soon as possible to avoid further costs of financial distress suggests that firms with alert and aggressive creditors should satisfy this condition.

Although we have established our approximations in the context of a simple model, our results rely on just a few elementary properties of the value of equity, which are likely to hold in a broad class of models used in applied work. First, the proof requires that the value of equity be a convex function of the value of assets with slope less than one, a property that is typical of structural credit risk models. Second, the proof requires that the value of equity is the only state variable following a diffusion. Thus, our results hold if there are other state variables, for the interest rate, market price of risk, or liability payments, as long as these are "slower moving" in the sense of being continuous-time 
Markov chains. ${ }^{9}$

It is easy to see, for example, that our first proposition holds as well in the model of Black and Scholes (1973) and Merton (1974). This is useful because we can use standard empirical implementations of this model to calculate an estimate of DI, over the sample for which we have liability data, and compare it to $1 / \sigma_{E}$. As explained in Appendix B, this estimate of DI makes an option adjustment to $1 / \sigma_{E}$ using the Black and Scholes (1973)'s formula. Figure 3 graphs the 95th, 50th, and 5th percentiles of this estimate of Black and Scholes's DI and compare them to the corresponding percentiles of $1 / \sigma_{E}$. The figure clearly indicates that that $1 / \sigma_{E}$ is indeed an upper bound for the Black and Scholes' DI. It also shows that the bound is quite tight for the 95th and 50th percentiles: this is important because we will later use these percentiles to define insolvency crises. We also note that because $1 / \sigma_{E}$ is an upper bound on DI, defining crises as times when $1 / \sigma_{E}$ falls below a low threshold can be considered conservative.

Based on these theoretical results, in the empirical work that follows, we approximate DI by the inverse of equity volatility, $1 / \sigma_{E}$. We term this approximation "measured DI". We estimate $1 / \sigma_{E}$ by the inverse of realized volatility, which we compute from the CRSP database on daily equity returns for each firm and each month from 1926 to $2012 .^{10,11}$ One may argue that, since the concept of financial soundness is fundamentally forward looking, DI should be measured using implied instead of realized volatility. An important drawback of using implied volatility, however, is that it is available only for selected stocks, and only for recent dates. Moreover, in Appendix C, we compare the distribution of realized versus implied volatilities, for the available data, and we show that the two track each other closely. We conclude that the benefits of using realized volatility largely outweigh the costs.

\footnotetext{
${ }^{9}$ See for example Hackbarth, Miao, and Morellec (2006) and Chen (2010) for versions of Leland's model in which the firm's cash flow process follows, under the risk-neutral measure, a modulated geometric Brownian motion.

${ }^{10}$ The CRSP daily data set on equity returns includes NYSE daily data beginning December 1925, Amex (formerly AMEX) daily data beginning July 1962, NASDAQ daily data beginning December 1972, and ARCA daily data beginning March 2006. We estimate $\sigma_{E}$ by the square root of the average squared daily returns in the month. We annualize this standard deviation by multiplying by $\sqrt{252}$ where 252 is the average number of trading days in a year.

${ }^{11}$ One could also compute realized volatility using a range of alternative methods including a rolling window of returns, or the latent-variable approach of stochastic volatility models. We have chosen our measure primarily to ensure that it does not use overlapping daily data and for the convenience of correspondence with the monthly calendar. Moody's uses a much longer window to compute equity volatility in its model.
} 


\section{Distance to Insolvency and Alternative Measures of Financial Soundness}

In this section we compare our measure of DI, based on equity volatility, to leading alternative measures of firms' financial soundness for those time periods in which we have data for these alternative measures.

First, we construct a mapping between the level of measured DI and Standard and Poor's credit ratings in the cross section. We use this mapping to interpret the level of measured DI in terms of these credit ratings.

We next validate our calibration of measured DI using credit ratings by comparing it to option adjusted bond spreads and credit default swap rates. Specifically, we compare the median measured DI to the median option-adjusted bond spreads, and to the median credit default swap rate, every month within portfolios of firms sorted by credit ratings. ${ }^{12}$ This approach is useful because these market-based measures are more responsive to market conditions than are slow-moving credit ratings.

We find that there is a strong linear relationship between the logarithm of median measured DI for these portfolios and the logarithm of median option-adjusted bond spreads and the logarithm of median credit default swap rates. We find that this relationship is roughly stable both in the cross section and in the time series. This is important because we are going to argue that one can construct a measure of financial crises based on the unconditional level of an economy-wide measure of DI.

Next we show a strong monotonic relationship between DI and Black and Scholes' Distance to Default (DD) for our portfolios of firms by credit ratings. Given the large empirical literature that uses distance to default as an indicator of firms' bond default and bankruptcy risk, we interpret this finding as indicating that measured DI should also be a strong indicator of firms' bond default and bankruptcy risk. We directly document the relationship between measured DI and bankruptcy in the cross section and time series.

\subsection{Measured DI and Credit Ratings}

To interpret the level of measured DI, we first study its cross-sectional relationship with credit ratings. Specifically, we compare the inverse of firms' equity volatility to their credit ratings as reported quarterly in COMPUSTAT. We pool all firm-month observations from 1985 to the present for which we simultaneously have a credit rating from COMPUSTAT

\footnotetext{
${ }^{12}$ By organizing firms into these portfolios, we are able to reduce the impact of sampling error in the estimation of firms' equity volatility on the empirical relationship between these alternative measures.
} 
and daily stock return data from CRSP. Each month, we place firms into credit ratings bins and then compute the median measured DI for all firm-month observations by ratings bin.

In Figure 4, we plot the median of the cross-sectional distribution of firms' measured DI conditional on Standard \& Poors (S\&P) credit rating. The figure reveals a clear monotonic relationship between the two: highly rated firms have a higher median measured DI. ${ }^{13}$ We emphasize four cutoffs. For highly rated firms (A and above), the median measured DI is 4 . For firms at the margin between investment grade and speculative grade (BBBvs. $\mathrm{BB}+$ ), the median DI is 3. For firms that are vulnerable (in the B range), the median measured DI is 2, whereas for firms that have filed for bankruptcy and/or have defaulted (C or D), the median measured DI is 1.

In further support of our calibration, in Figure 5, we plot the frequency in the pooled firm-month data of firms having an investment grade rating (BBB- and above) conditional on values of measured DI. ${ }^{14}$ The frequency of firms having an investment grade rating increases sharply with measured DI for rated firms: it is less than $15 \%$ if measured DI is below 1, and more than $80 \%$ if measured DI is above 4. For DI's between 1 and 2, this probability is 30\%, for DI's between 2 and 3, it is just under $50 \%$ and finally for measured DI's between 3 and 4, it is $65 \%$. Thus, a measured DI below 1 strongly indicates that a firm has a speculative grade rating, and a measured DI above 4 strongly indicates a firm has an investment grade rating.

Finally, we also consider the frequency in the pooled firm-month data of firms being what S\&P calls "highly vulnerable" (a rating of CC and below), conditional on values of DI. For firms with measured DI less than 1, this frequency is about $10 \%$ and for firms with measured DI's between 1 and 2, it is about $1.4 \%$. To interpret these conditional probabilities, note that the unconditional probability of a rating $\mathrm{CC}$ and below is very small, about $0.75 \%$. Taking this into account, a firm with measured DI below 1 is thirteen times more likely to be highly vulnerable than a randomly chosen firm. A firm with a measured DI between 1 and 2 is twice more likely to be highly vulnerable.

Given these findings, we propose the following benchmark calibration to interpret the level of measured DI:

- measured DI above 4: good and safe.

\footnotetext{
${ }^{13}$ In fact, our data indicates that monotonicity holds for all percentiles. This means that, in the crosssection, a higher credit rating corresponds to a higher measured DI, in the sense of first-order stochastic dominance.

${ }^{14}$ It is important to note that the unconditional distribution of firms' credit ratings is biased towards higher ratings since firms select into being rated.
} 
- measured DI of 3: borderline between investment and speculative grade.

- measured DI of 2: vulnerable.

- measured DI below 1: highly vulnerable.

\subsection{Measured DI and Bond Credit Spreads}

We now consider the relationship between measured DI and credit spreads in bond yield data. Bank of America-Merrill Lynch (BAML) calculates daily data on option-adjusted bond spreads ${ }^{15}$ for a large universe of corporate bonds whose yields underlie BAML's corporate bond indices. BAML then groups firms into portfolios by rating class, for the seven ratings classes AAA to CCC and below and reports an index of the option-adjusted spread on bonds of firms in each portfolio. These daily data on option adjusted bond spreads by ratings class are available from 1997 to $2012 .{ }^{16}$ We compute monthly averages of daily option-adjusted spreads on these indices and, in Figure 6, we plot the logarithm of these option adjusted bond spreads against the logarithm of median measured DI for firms in the same ratings class bin in the same month. We plot separately the pre-August 2007 data (with blue triangles) and post-August 2007 data (with red circles). Note two sources of variation are shown in this figure: variation in measured DI and bond spreads across credit ratings classes at a point in time and variation over time in measured DI and bond spreads by ratings class.

Clearly, credit spreads are decreasing in measured DI, and the relationship is linear in logs. This relationship is relatively tight: the $R^{2}$ 's from a regression of log optionadjusted spread on log measured DI for data pre- and post-August 2007 are 0.74 and 0.79 , respectively. For another way to see that measured DI is strongly indicative of credit spreads, note that having a low measured DI and a low credit spread is very rare. In particular, no portfolio has a measured DI below 1 and an option-adjusted spread below 400bp. Likewise, it is very rare to have a high measured DI (above 4) and a high credit spread (above 400bp). We conclude from the data on measured DI and optionadjusted spread, that measured DI captures a significant amount of the information in credit spreads, and this helps to validate DI as a measure of financial soundness.

Note as well that the linear relationship in logs between measured DI and bond spreads is quite stable in the data pre-August 2007 and post-August 2007. We interpret this finding as indicating that during the financial crisis of 2008 , both measured DI and bond

\footnotetext{
${ }^{15}$ The option adjustment here is intended to correct bond spreads for features of corporate bonds, such as callability, that do not correspond to default risk and yet might impact observed bond spreads.

${ }^{16}$ These data are available in the data repository FRED at the Federal Reserve Bank of St. Louis.
} 
spreads as indicators of financial soundness deteriorated over time in the same relative proportion as they do typically at a point in time across the spectrum of firms of different credit qualities.

\subsection{Measured DI and Credit Default Swap Rates}

In the past decade, a broad market in credit default swaps has emerged. Credit default swaps have a payoff, contingent upon default, that is equal to the value of the defaulted bond relative to its face value. Thus, CDS rates offer a natural market-based measure of corporate default risk which we can compare to measured DI.

We use data from Markit on single-name five-year CDS rates from 2001 through 2011. We construct monthly averages of daily swap rates by firm. We then merge this CDS swap rate data with our monthly DI data from CRSP by CUSIP using Markit's Reference Entity Dataset, then hand and machine-check the results of our merge. Finally, we bin firms by ratings class into seven ratings classes from AAA to CCC and below to reduce noise, and we compute the median CDS rate and median measured DI monthly by rating class.

Figure 7 plots measured DI versus CDS rates by ratings class for 2001-2011. We use a log scale because the relationship between measured DI and CDS rates is, like the relationship between measured DI and option-adjusted bond spreads, close to log linear. The plot shows a clear negative relationship between CDS rates and measured DI. It also adds further credibility to our calibration, since relatively few observations with a measured DI less than 2, and very few observations with a measured DI less than 1, correspond to a CDS rate below 400bp. Conversely, very few observations have a measured DI greater than 4 and a CDS rate above 200bp. We separate the data preAugust 2007 and post-August 2007 to support our calibration in levels that are constant over time. The $R^{2}$ from a regression of log CDS rate on log measured DI is 0.76 for the data pooled by credit rating pre-2007 and 0.67 post-2007. ${ }^{17}$ Although the slope and intercept coefficients differ across these two samples, our calibration appears robust, since in both time periods a measured DI below 1 corresponds to a CDS rate of 400bp, and a DI above 4 corresponds to a CDS rate below 200bp.

\subsection{Measured DI and Bankruptcy}

We now consider the relationship between DI and bankruptcy measures. We first compare our measure of DI to Black and Scholes' Distance to Default (DD). A large empirical

\footnotetext{
${ }^{17}$ The same regression using firm-level data for the whole sample yields similar coefficients and an $R^{2}$ of over $30 \%$.
} 
literature in corporate finance examines the performance of DD as an indicator of the likelihood that a firm will declare bankruptcy and/or default on a bond. Duffie et al. (2009) and Duffie et al. (2007) document the economic importance of distance to default in determining default intensities. ${ }^{18}$ Duffie (2011) is an important recent survey of such work. Moody's Analytics produces and sells estimates of the likelihood that publicly traded firms will default on their bonds using a similar methodology (Sun, Munves, and Hamilton, 2012). The work of Bharath and Shumway (2008) suggests that our simple DI measure should capture much of the relevant information in DD about default probabilities.

To calculate DD, we use data on a firm's equity value and volatility, together with accounting data on the firm's liabilities, and we follow a procedure outlined in Duffie (2011) based on Black and Scholes' option pricing formula. See Appendix B for details. ${ }^{19}$ In Figure 8 we show a scatter plot of our computed DD against measured DI, monthly from December 1985 to December 2012, for the seven rating classes AAA to CCC and below. While the scale obviously differs, since our DI is measured in levels and DD is measured in logs, the figure shows a clear positive relationship between the two.

To confirm that measured DI has implications for real outcomes, we also briefly document the relationship between measured DI and bankruptcy. ${ }^{20}$ For our purposes, we establish two facts. First, in the cross section, we show that DI decreases monotonically as firms become closer and closer to bankruptcy. This corroborates our calibration. Then, in the time series, we show that the fraction of firms with low measured DI is strongly correlated with the aggregate default rate. Thus, even though measured DI is based on market prices, and is thus driven by both fundamental risk and potentially time-varying risk premia, measured DI and actual default events are related both in the cross section and in the time series. The default decision seems to be related to measured DI regardless of the driver of measured DI.

We first examine the evolution of measured DI as a firm progresses toward bankruptcy. To do so, we merge the data on bankruptcy filings by publicly traded firms collected by Chava and Jarrow (2004) with that in the UCLA-LoPucki bankruptcy database. In Figure 9, we show the $5 \mathrm{th}, 10 \mathrm{th}, 25 \mathrm{th}, 50 \mathrm{th}, 75 \mathrm{th}$, 90th, and 95th percentiles of the distribution of the distance to insolvency for those firms that end up filing for bankruptcy in the 36 months prior to filing for bankruptcy or being delisted. As one can see, these percentiles

\footnotetext{
${ }^{18}$ Duffie et al. (2007) report that a $10 \%$ reduction in distance to default causes an estimated $11.3 \%$ increase in default intensity, and that distance to default is the most economically important determinant of the term structure of default probabilities.

${ }^{19}$ Note that this Distance to Default, which is the one commonly used in the literature, is measured in "log" units. In equation (2) we defined a related measure in levels to make it directly comparable to DI.

${ }^{20}$ See Bharath and Shumway (2008) for a systematic empirical comparison of structural and nonstructural models of default prediction.
} 
decline monotonically as bankruptcy approaches. A year prior to bankruptcy, 90\% of these firms have a measured DI that is below the cutoff of 3 for investment grade, and $50 \%$ are near the cutoff of 1 for being highly vulnerable. At bankruptcy, all firms have a measured DI below 2, associated with being vulnerable, and nearly all firms have a measured DI below 1, associated with being highly vulnerable.

Next, we consider the relationship between the distribution of measured DI and aggregate default rates. We use Exhibit 30 in Moody's (2012), which documents annual issuer-weighted corporate default rates for all rated corporations. For comparability, we construct an annual series of measured DI by computing firm-level volatilities over an annual window. In Figure 10, we plot the fraction of firms with measured DI less than 1, against Moody's aggregate default rate series. The figure reveals that the two series are highly correlated, with a correlation of 0.82 . Even if we use the fraction of firms with annual measured DI less than 2, the correlation of this fraction with Moody's annual default rates is 0.72 . Thus, we conclude that the fraction of firms with low measured DI is highly correlated with realized annual default rates.

\section{Financial Soundness, 1926-2012}

We now use our measure of DI to retrace the history of U.S. firms' financial soundness, from 1926 to the present. Our interest is to characterize the evolution of the cross-sectional distribution of distance to insolvency across firms at a monthly frequency over this time period. We first show that this distribution is approximately lognormal each month from 1926 to 2012 and hence can be characterized by two moments of the distribution. We then show that most of the movements in this distribution are accounted for by changes in the cross-sectional mean of log measured DI rather than by changes in its cross-sectional standard deviation. We then define episodes that we term insolvency crises in terms of movements in the distribution of distance to insolvency across firms and examine our three empirical questions regarding the relationship between insolvency crises and business cycles over this long historical time period.

\subsection{A Lognormal Approximation}

Figure 11 displays the cross-sectional distribution of measured DI across firms over the 1926-2012 period, by plotting the time series of the 5th, 10th, 25th, 50th, 75th, 90th, and 95th percentile cutoffs for firms' measured DI. To analyze this distribution in a simple way, we first argue that the log of measured DI is approximately normally distributed. 
Figure 11 suggests this, since it shows that the distribution of measured DI appears to fan out at high levels: the higher percentiles cutoffs are further apart than the lower ones. It is intuitive that taking logs would make the percentile cutoffs more evenly distributed.

More formally, consider the following empirical diagnostic for a lognormal distribution, in the spirit of the Kolmogorov Smirnov specification test. If the cross-sectional distribution of DI were truly lognormal, with the estimated cross-sectional mean and standard deviation in each month, then the transformed variable

$$
N\left(\frac{\log \left(D I_{t}\right)-\operatorname{mean}_{t}}{\text { standard deviation }_{t}}\right)
$$

should be uniform, where $N(\cdot)$ is the cumulative distribution of a standard normal distribution. Figure 12 plots the 5th, 10th, 25th, 50th, 75th, 90th, and 95th empirical percentile cutoffs of this transformed variable over time, for each month 1926-2012. If measured DI were truly lognormal in the cross section, then the transformed variable should be uniform and its percentiles should be exactly equal to $0.5,0.25,0.5,0.75,0.90$, and 0.95 in each month. One sees in the figure that this is approximately true: the empirical percentile cutoffs do not deviate much from these values. We thus conclude that measured DI is approximately lognormal in the cross section each month. This is convenient, since we can then approximately characterize the entire distribution each month with its mean and standard deviation.

Figure 13 plots the time series of the cross-sectional mean and standard deviation of $\log$ measured DI. One sees that there are some fluctuations in the standard deviation over time, notably as stocks from new exchanges are added to CRSP. However, these fluctuations are much smaller than those of the mean. This suggests that time variations of the cross-sectional mean of log measured DI account for most of the time variations of the entire cross-sectional distribution. To illustrate this, consider Figure 14, which shows the true 95th percentile of log measured DI (in red) versus an approximate 95th percentile, calculated assuming that the log of measured DI is normally distributed with a constant standard deviation, equal to the 1926-2012 average. The 95th percentile of a lognormal distribution is equal to mean $_{t}+N^{-1}(0.95) \times$ standard deviation $_{t}$, so in principle it could be quite sensitive to fluctuations in standard deviation. One sees, however, that, empirically, most variations of the 95th percentile are accounted for by variations of the mean. 


\subsection{Insolvency Crises and Recessions}

From now on we study time variations in one moment of the measured DI distribution: the median. We use our calibration to focus on one particular cutoff for median measured DI and define a deep insolvency crisis as one in which the median measured DI falls below 1. In deep crises, half of publicly traded firms have a measured DI associated with a highly vulnerable credit rating.

Although we point to particular dates as insolvency crises based on this calibrated cutoff, the entire time series of the median measured DI can also be used as a continuous measure of the financial soundness of all U.S. firms. This is an advantage over discrete, or "indicator" measures. The median is also a useful summary statistic for the entire

distribution. Indeed, recall that log measured DI is approximately lognormal, so the log of median is approximately equal to the mean of log. Moreover, we established that the cross-sectional standard deviation fluctuates much less than the mean over time. Thus, in a deep insolvency crisis, the large negative shift in median measured DI is associated with approximately parallel negative shifts, in a log scale, of all other percentiles of measured DI.

To assess the size of these negative shifts, consider the following calculation. In a deep crisis, log measured DI is approximately normally distributed, with a cross-sectional mean equal to zero, the log of the median, and a standard deviation that is roughly equal to 0.61 (1.8 in level), its historical average. Hence, during a deep crisis about $N\left(\frac{\log 3}{0.61}\right) \simeq 96 \%$ of publicly traded firms have a measured DI below 3 associated with speculative grade rating, and about $N\left(\frac{\log 2}{0.61}\right) \simeq 87 \%$ of publicly traded firms have a measured DI below 2 associated with a vulnerable credit rating. Hence, deep financial crises are also broad.

Figure 15 plots the median measured DI over time against a log scale and shows the deep insolvency crises that occurred in October of 1929 and the Great Depression, the fall of 1937, and the fall of 2008. During these times, 50\% of firms became highly vulnerable, with a measured DI below 1. Thus, in relation to business cycles over this time period, the worst recessions (the Great Depression and the Great Recession) coincide with deep insolvency crises. One can also see in Figure 14 that, in the 1932-1933 and 2008 insolvency crises, $95 \%$ of firms had a measured DI below 2, well below the cutoff of 3 for investment grade. Thus, these crises are even broader than suggested by the lognormal approximation with constant cross-sectional standard deviation.

In sum, when we define an insolvency crisis as a time during which the median measured DI falls below 1, the Great Depression and the Great Recession stand out as singular events. On the other hand, other severe recessions, such as that in 1981-1982, are not associated with insolvency crises. The median measured DI does indicate one other in- 
solvency crisis in October 1987, corresponding to the dramatic stock market crash during that month, but this episode did not correspond to a recession. This episode also looks milder from the perspective of how broad the insolvency contraction was; Figure 14 shows that unlike during the Great Depression and Great Recession, the 95th percentile of measured DI was closer to the cutoff of 3 instead of 2 .

This finding that the recessions of 1932-1933, 1937, and 2008 are distinctive in being associated with insolvency crises is not particularly sensitive to the thresholds used to define insolvency crises. The next candidate episodes that could be termed insolvency crises if a higher threshold is used correspond to the events of World War II and the immediate postwar period leading into the Cold War, and the period from 1998-2002 corresponding to the Russian default crisis and the tech stock market boom and bust, neither of which correspond to large sustained recessions.

Next, we investigate the contributions of leverage and asset volatility to movements in the distribution of measured DI.

\subsection{Leverage versus Asset Volatility}

Given the definition of leverage adjusted for asset volatility and the relationship of this concept to DI, an insolvency crisis can occur for two reasons: one due to an increase in leverage (a drop in the equity cushion, $\frac{V_{A t}-V_{B t}}{V_{A t}}$ ) and the other due to an increase in asset volatility (an increase in business risk, $\sigma_{A t}$ ). In this section, we decompose DI into its leverage and asset volatility components to study the contribution of each to the level of DI over time. We provide evidence that the contribution of asset volatility to financial soundness is at least as important or more important than the contribution of leverage.

Most of the current literature on financial frictions in macroeconomics envisions that the shock that drives a deterioration in the distribution of financial soundness across firms is a decline in asset values $V_{A t}$ and hence an increase in leverage. Moreover, most models of agency costs focus on the effects of changes in leverage alone on managerial and equity holder decisions. Our empirical decomposition below suggests that, in order to understand insolvency crises, this literature must consider shocks that increase not only firms' leverage but also their asset volatility.

We begin with a simple benchmark, assuming unlimited liability, and then compare asset volatility under this assumption to asset volatility using Black and Scholes' model to compute the value of the option to default. ${ }^{21}$ Under unlimited liability, $V_{A t}=V_{E t}+V_{B t}$,

\footnotetext{
${ }^{21}$ See Appendix B for details.
} 
and thus we can decompose log DI into leverage and asset volatility simply using

$$
\log \left(\frac{1}{\sigma_{E t}}\right)=\log \left(\frac{V_{A t}-V_{B t}}{V_{A t}}\right)+\log \left(\frac{1}{\sigma_{A t}}\right) .
$$

Specifically, in this decomposition, the mean of log DI, which we have argued is a good proxy for the position of the entire cross-sectional distribution of DI, is equal to the mean of log leverage and the mean of the log of firms' inverse asset volatility.

We use quarterly COMPUSTAT data on total liabilities as an estimate of $V_{B t}$, and we use daily equity values at the end of the quarter to compute $V_{E t}$. Note that although our estimate of $V_{B t}$ based on book values might be slow moving, our estimate of leverage moves on a daily basis due to fluctuations in $V_{E t}$. Figure 16 plots the mean log distance to insolvency and asset volatility terms in equation (4), for the 1972-2012 time period. Clearly, most of the changes in the level of DI is due to changes in the level of asset volatility, especially in more recent data.

To show more clearly the relative contribution of leverage and asset volatility, Figure 17 calculates a counterfactual time series by shifting the median $\log \left(1 / \sigma_{E}\right)$ up by a constant, so that it has the same historical mean as the median $\log \left(1 / \sigma_{A}\right)$, thus obtaining a "constant leverage" measure of $\log \left(1 / \sigma_{E}\right)$. The figure strongly suggests that most of the variation in DI is accounted for by variation in asset volatility. Of particular interest is the role of leverage versus asset volatility in the insolvency crisis of 2008. Figure 17 shows that this crisis was almost entirely due to an increase in asset volatility. This is in contrast to common narratives in the financial press and academic literature, which emphasize the role of an increase in leverage due to a fall in asset values in driving the deterioration in financial soundness in 2008.

One may wonder whether these decomposition results are biased by our assumption of unlimited liability. To address this concern, Figure 18 plots option-adjusted asset volatility. The figure shows that the option adjustment using Black and Scholes' model is very minor.

As further evidence of the major contributing role of asset volatility over leverage in determining firms' financial soundness in 2008, we use the decomposition under unlimited liability to compare the percentiles of the cross-sectional distribution of DI in October 2008 with the cross-sectional distribution of DI in October 2008 that would have occurred if leverage for each firm had remained at its level from October 2007 and only asset volatility had risen to its level in October 2008.

These percentiles are shown in Figure 19. The first column of colored bars shows the 5th, 10th, 25th, 50th, 75th, 90th, and 95th percentiles of the cross-sectional distribution 
of DI in October 2007. The second column of colored bars shows the 5th, 10th, 25th, 50th, 75th, 90th, and 95th percentiles of the cross-sectional distribution of DI in October 2008. The third column of colored bars shows the 5th, 10th, 25th, 50th, 75th, 90th, and 95th percentiles of the cross-sectional distribution of DI computed firm-by-firm using that firm's leverage in October 2007 and its asset volatility in October 2008. As is clear in the figure, the percentiles of this counterfactual cross-sectional distribution shown in the third column are quite similar to those found for the actual distribution in October 2008 (shown in the second column) and quite different from those found for the cross-sectional distribution in October 2007 (shown in the first column).

This cross-sectional decomposition provides further evidence that the collapse in the distribution of DI in the fall of 2008 is, in an accounting sense, primarily due to an increase in asset volatility rather than an increase in leverage.

The Chicago Board of Option Exchange Volatility Index (VIX) is often used as a measure of financial stability and/or macroeconomic uncertainty. Figure 20 plots our measure of DI for returns on the value-weighted portfolio from CRSP along with the median measured DI in the cross-sectional distribution across individual firms. (We use the DI of the value-weighted portfolio rather than VIX since these data are available from 1926 on. For recent data, the comparison using VIX is very similar.) As one can see in the figure, DI for the value weighted portfolio closely tracks median measured DI in insolvency crises. Thus, one interpretation of our findings is that we are giving a structural interpretation of why high VIX states are bad macroeconomic states. When the VIX is high, firms have smaller effective equity cushions because firms' underlying business risk is substantially higher, and expected costs of financial distress are higher as a result. ${ }^{22}$

\subsection{Financial versus Nonfinancial Firms}

A large literature in macroeconomics and finance argues that, when financial intermediaries are financially unsound, they amplify and propagate negative shocks to the real economy. In fact, a commonly held view is that the weak financial soundness of financial intermediaries was the root cause of the large recessions of 1932-1933, 1937, and 2008. A growing literature also argues that changes in regulation and/or the introduction of new financial products changed the risk-taking behavior of financial institutions.

To shed light on the relative financial soundness of financial versus nonfinancial firms

\footnotetext{
${ }^{22}$ The decomposition of volatility into an aggregate, industry, and firm-specific component is the focus of Campbell, Lettau, Malkiel, and Xu (2001). Their Figures 2-4 graph this decompostion and show the importance of firm-specific volatility in overall firm volatility. They also show a substantial correlation between the three volatility series.
} 
over time, we compare the distribution of measured DI over time for financial and nonfinancial firms. ${ }^{23}$ An advantage of our measure is that we do not require accounting or market value information for liabilities, which are hard to measure properly for financial firms. Like any market-based measure, however, our measure of DI based on equity volatilities is influenced by the presence (implicit or explicit) of government subsidies. ${ }^{24}$ We also acknowledge that the use of market-based signals for regulation is subject to the usual caveats regarding adverse feedback loops between agents' actions and market prices. $^{25}$

We begin by classifying financial firms as those firms in CRSP with an Standard Industrial Classification (SIC) code in the range of 6000-6999, and comparing the median measured DI for financial firms and non-financial firms. We measure the Distance to Insolvency for these financial firms in exactly the same way as we do for all firms. Figure 21 graphs the median measured DI for financial and nonfinancial firms from 1926 to 2012. The two series coincide for the first half of the sample, and in the second half, financial firms appear more sound than nonfinancial firms outside of the recent financial crisis. One challenge in interpreting this graph is that the characteristics of the two firm populations are likely to be quite different. Another challenge is that many firms with SIC codes from 6000 to 6999 are not banks, or at least not typical financial firms. We address these challenges in two ways. First, we compare large financial firms to large nonfinancial firms. Then, we study a set of firms that we call government-backed large financial institutions, or GBLFIs.

Figure 22 plots the median measured DI for the 50 largest financial and nonfinancial firms by market capitalization from 1962 to 2012, the period for which there are enough large firms of each type. The main message from this graph is that the median financial soundness of large financial and large nonfinancial firms was quite similar over this time period. From the collective evidence in Figures 21 and 22, it is hard to argue that changes in bank regulation or financial innovations lead large financial firms to add leverage relative to their business risk in a manner different from their large nonfinancial peers.

Our final comparison is to a set of ex post systemically important institutions that we term GBLFIs. This set of institutions comprises the 18 bank holding companies that currently participate in the Federal Reserve's annual stress tests and eight large financial

\footnotetext{
${ }^{23}$ See Giammarino, Schwartz, and Zechner (1989) for an early contribution using a structural model of default to consider market-implied valuations of bank assets and the value of deposit insurance.

${ }^{24}$ Kelly, Lustig, and Van Nieuwerburgh (2013a) and Lustig and Gandhi (forthcoming) present evidence that goverment subsidies are evident in bank stock returns and option prices.

${ }^{25}$ See Bond, Goldstein, and Prescott (2010), which provides an equilibrium analysis of the use of market signals in regulation.
} 
institutions that failed during the crisis (AIG, Bear Stearns, Fannie Mae, Freddie Mac, Lehman, Merrill Lynch, Wachovia, and Washington Mutual). The full list of GBLFIs together with the dates for which data on their equity returns are available, is provided in Table 1.

Figure 23 plots the median measured DI for the GBLFIs and the 50 largest nonfinancial firms by market capitalization from 1962 to 2012. Again, there does not seem to be evidence in market prices of increased risk taking by the GBLFIs relative to non-financial firms over the period July 1962--July 2007. However, it does appear that the distance to insolvency for the GBLFIs deteriorated relative to their nonfinancial peers starting in August of 2007 and fell to an extremely low level in the depth of the crisis from October 2008 to March 2009. Moreover, these firms have been slower to recover their DI since that time.

One goal of financial regulation is to identify relatively weak financial institutions in the cross section either before a crisis begins or during the crisis. We are skeptical that regulators can achieve this goal because we find that most of the movements of measured DI, even for the GBLFIs are systemic in nature - measured DI for all of these institutions moves closely together. Figure 24 plots the 90th, 50th, and 10th percentiles of the distribution of measured DI for the GBLFIs. The figure presents clear evidence that the cross-sectional variation in measured DI for these GBLFIs in any given month is quite small relative to the movement in the distribution of DI over time: during this time period, the risk that any one GBLFI is unsound compared with the others is small relative to the risk that the whole group of GBLFIs becomes unsound together. This pattern is particularly apparent in the fall of 2011: these figures indicate that the whole group of GBLFIs was nearly as unsound at that time as the group was in early 2008 or mid-2009.

\section{Conclusion}

This paper is intended as a contribution to measurement: we propose a simple and transparent method for measuring the financial soundness of firms that can be broadly applied to all publicly traded firms in the economy.

We identify three recessions in which a macroeconomic downturn coincides with or follows shortly after a substantial insolvency crisis: 1932-1933, 1937, and 2008. We find that the other recessions in this time period are not associated with significant deteriorations or insolvency crises. Of course, since our findings uncover only a correlation (or lack thereof) between insolvency crises and recession, they do not establish causation. 
We do, however, see our findings as consistent with the hypothesis that financial frictions may have played a significant role in the recessions of 1932-1933, 1937, and 2008, and that financial frictions (as envisioned by current theories) did not play a significant role in other recessions during this time period. We hope that our research will provoke more detailed studies of the differences between these three recessions and other recessions to see if a stronger empirical and theoretical basis for causal links between financial frictions and the evolution of the macroeconomy can be developed.

A decomposition of our distance to insolvency measure into its leverage and asset volatility components attributes almost all of the 2008 insolvency crisis to an increase in asset volatility, or business risk. Distortions to managerial and equity holder decisions occur when the likelihood of insolvency is high for either reason. Thus, considering only the effects of leverage on agency costs may leave out quantitatively important variation due to time-varying asset volatility. We see this question as being of first-order importance for future research in order to understand the sources of these large changes in asset volatility.

We also find little or no evidence that the evolution of financial soundness across financial firms differs meaningfully from that for all firms, even during the three crisis episodes. In the recessions of 1932-1933, 1937, and 2008, the timing and magnitude of the insolvency crisis were the same as those for all firms, financial or nonfinancial, large or small. We find only weak evidence that the distribution of financial soundness for a set of systemically important financial institutions deteriorated in a distinctive manner in advance of the most recent financial crisis.

Finally, we find it distressing that government-backed large financial institutions have continued to appear weak in terms of their financial soundness since the summer of 2007 , in spite of the heightened regulatory scrutiny they have received. Why these firms continue to look financially weak relative to their peers is an open question that calls for further research. 


\section{A Leland (1994) structural model}

Under the true "physical" measure, the value of the firm's assets, $V_{A}$, follows a geometric Brownian motion with drift $\mu_{A}$ and volatility $\sigma_{A}$. The firm pays a dividend $\delta V_{A}$ per period. Under the risk-neutral measure, the value of the firm's assets follows

$$
d V_{A t}=(r-\delta) V_{A t} d t+\sigma_{A} V_{A t} d B_{t}^{Q}
$$

The intuition for the risk-neutral drift of $r-\delta$ is simply that, under the risk-neutral measure, the expected return from buying the assets at $V_{A t}$, selling at $V_{A t+d t}$, and receiving the dividend flow $\delta V_{A t} d t$ should be equal to $r d t$. Assume that the equity holders have to pay $c$ (per unit of time) to the debt holders until either (i) equity holders choose to default or (ii) creditors exercise their right to force equity holders to default, when the value of the assets reach a protective covenant threshold $V_{A}^{P}$. Let $\tau_{P}$ be the first time the asset value falls below the protective covenant threshold, $V_{A}^{P}$. The problem of the equity holder is to choose a stopping time $\tau$ in order to solve

$$
w\left(V_{A}\right)=\sup _{\tau} \mathbb{E}^{Q}\left[\int_{0}^{\tau \wedge \tau_{P}}\left(\delta V_{A t}-c\right) e^{-r t} d t\right] .
$$

Consider equity holders starting with two different initial levels of assets, $V_{A 0}<V_{A 0}^{\prime}$. Clearly, the equity holders starting with $V_{A 0}^{\prime}$ can always mimic the policy of equity holders and creditors starting at $V_{A 0}$ and would earn a higher payoff, implying that $w\left(V_{A}\right)$ is nondecreasing. This also shows that an optimal policy is of the threshold form: there is a $V_{A}^{\star}$ such that when $V_{A} \leq V_{A}^{\star}$, equity holders default, or are forced into default by creditors, and continue operating the firm otherwise. Thus, the Bellman equation for the value of equity is

$$
\begin{aligned}
& V_{A} \leq V_{A}^{*}: w\left(V_{A}\right)=0 \\
& V_{A} \geq V_{A}^{*}: r w\left(V_{A}\right)=-c+\delta V_{A}+w^{\prime}\left(V_{A}\right)(r-\delta) V_{A}+w^{\prime \prime}\left(V_{A}\right) \frac{\sigma_{A}^{2}}{2} V_{A}^{2} .
\end{aligned}
$$

A particular solution to the second-order ordinary differential equation (ODE) is $V_{A}-V_{B}$, where $V_{B}=c / r$. The general solution of the corresponding homogeneous ODE is of the form $K_{1} V_{A}^{\phi}+K_{2} V_{A}^{-\theta}$, where $K_{1}$ and $K_{2}$ are constant, and $\phi$ and $\theta$ are the positive roots 
of

$$
\begin{aligned}
& \phi^{2} \frac{\sigma_{A}^{2}}{2}+\phi\left(r-\delta-\frac{\sigma_{A}^{2}}{2}\right)-r=0 \\
& \theta^{2} \frac{\sigma_{A}^{2}}{2}-\theta\left(r-\delta-\frac{\sigma_{A}^{2}}{2}\right)-r=0 .
\end{aligned}
$$

When $V_{A} \rightarrow \infty$, the value of equity has to asymptote to $V_{A}-V_{B}$, implying that $K_{1}=0$. The constant $K_{2}$ is found by value matching $w\left(V_{A}^{*}\right)=0$, which delivers

$$
K_{2}=f\left(V_{A}^{\star}\right) \text { where } f(x) \equiv-\left(x-V_{B}\right) x^{\theta} .
$$

The optimal threshold maximizes $f(x)$ subject to $x \geq V_{A}^{P}$. Differentiating $f(x)$ with respect to $x$ reveals that it is hump shaped and reaches a unique maximum at $\frac{\theta}{1+\theta} V_{B}$. Therefore, the optimal threshold is

$$
V_{A}^{\star}=\max \left\{V_{A}^{P}, \frac{\theta}{1+\theta} V_{B}\right\} \text { and } w\left(V_{A}\right)=V_{A}-V_{B}-\left(V_{A}^{\star}-V_{B}\right)\left(\frac{V_{A}}{V_{A}^{\star}}\right)^{-\theta} \text {. }
$$

Convexity follows because $V_{A}^{\star} \leq V_{B}$ by our assumption that $V_{A}^{P} \leq V_{B}$. Simple calculation shows that $w^{\prime}\left(V_{A}^{*}\right) \geq 0$ and that $w^{\prime}(\infty)=1$, implying that $w\left(V_{A}\right)$ is nondecreasing and has a slope less than one.

\section{B Calculating $V_{A}$ and $\sigma_{A}$ using Black and Scholes}

Following the empirical literature, we can use the Black and Scholes's model to calculate asset values, $V_{A}$, and volatilities, $\sigma_{A}$, using data on equity values and accounting data on liabilities. We use the values of $V_{A}$ and $\sigma_{A}$ can then be used to calculate an estimate of DI as defined in equation (1), or to calculate Black and Scholes (1973)'s DD, as defined in Section 3.4.

The algorithm. calculate Black and Scholes (1973)'s DD using an iterative algorithm that closely follows Vassalou and Xing (2004) and Duffie (2011). For each publicly traded firm in our sample, we assume that the value of the assets, $V_{A}$, is a geometric Brownian motion with volatility $\sigma_{A}$. We view equity as a call option with an underlying equal to the value of the assets, $V_{A}$, a maturity equal to one year, and a strike price equal to $V_{B}$. Under these assumptions, the Black and Scholes' formula implies that the value of equity 
is given by:

$$
V_{E}=N\left(d_{1}\right) V_{A}-N\left(d_{2}\right) V_{B} e^{-r}
$$

where $N(\cdot)$ is the cumulative distribution function of a standard normal random variable, and

$$
d_{1} \equiv \frac{\log \left(V_{A}\right)-\log \left(V_{B}\right)+r+\frac{\sigma_{A}^{2}}{2}}{\sigma_{A}}, \text { and } d_{2}=d_{1}-\sigma_{A} .
$$

The iterative algorithm. We initialize our iterative algorithm for calculating $V_{A}$ and $\sigma_{A}$ by setting $V_{A}^{(0)}=V_{E}+V_{B}$, where $V_{E}$ is the market capitalization of the firm, calculated using the CRSP data on price and number of shares outstanding. Following the literature, we take $V_{B}$ to be the the sum of short term liabilities, and half of long-term liabilities, as given in COMPUSTAT. Consistent with Gilchrist and Zakrajsek (2012), for each firm we restrict attention to those times during which quarterly data are available, and we linearly interpolate between points to obtain daily data.

At step $n$ of our algorithm, we have a candidate time series $V_{A}^{(n)}$ for the value of the assets on each day of our sample. Given $V_{A}^{(n)}$, we obtain a daily time series for asset realized volatility, $\sigma_{A}^{(n)}$, by computing the annualized square root of the average squared daily returns on the assets during the month. Given $V_{A}^{(n)}$ and $\sigma_{A}^{(n)}$, we use equation (8) to calculate a time series for $d_{1}^{(n)}$ and $d_{2}^{(n)}$. To deal with firms with small liabilities, we cap $\log \left(V_{A}^{(n)} / V_{B}\right)$ at 4 (the results turn out to be largely insensitive to this). In applying the formula, we take the interest rate to be the one-year Treasury constant-maturity (daily frequency) from the Federal Reserve's H.15 report. We then use equation (7) to obtain a new candidate time series for the value of the assets:

$$
V_{A}^{(n+1)}=(1-\omega) V_{A}^{(n)}+\omega \frac{V_{E}+N\left(d_{2}^{(n)}\right) V_{B} e^{-r}}{N\left(d_{1}^{(n)}\right)},
$$

where $\omega$ is a relaxation parameter, which we set equal to 0.2 to improve convergence. We terminate our algorithm when the norm of $\left(V_{A}^{(n+1)}-V_{A}^{(n)}\right) / V_{A}^{(n)}$ is less than $10^{-5}$. Convergence occurs for over $95 \%$ of the stocks in the sample.

An estimate of DI. Using the values of $V_{A}$ and $\sigma_{A}$ implied by Black and Scholes (1973), and the liability $V_{B}$ measured as above, one obtains an estimate of DI using equation (1). The percentiles resulting distribution of DI are shown in Figure 3. 
Black and Scholes' DD. Following the literature, the Black and Scholes' and Merton distance to default is defined as

$$
D D \equiv \frac{\log \left(V_{A}\right)-\log \left(V_{B}\right)+\mu_{A}-\frac{\sigma_{A}^{2}}{2}}{\sigma_{A}},
$$

where $V_{A}$ and $\sigma_{A}$ are calculated using the iterative algorithm described above, and $\mu_{A}$ is the mean return on the assets over the time period.

\section{Realized versus Implied Volatility}

As a robustness check on our empirical implementation of our DI measure, we compare median DI computed using realized and option-implied volatilities from option metrics. We focus on the median log DI since, as argued in Section 4.1, its fluctuations account for most of the fluctuations in the overall DI distribution. Figure 25 plots the time series of the median log DI measured using implied and realized volatility from OptionMetrics for the available data from 1996 to 2013. We use their daily data for both series to ensure that the same firms are included in both samples. We use the implied volatility from OptionMetrics' standardized, at the money, options with 30 days to maturity, and pool both calls and puts. The figure shows that realized volatility closely tracks fluctuations of implied volatility. 


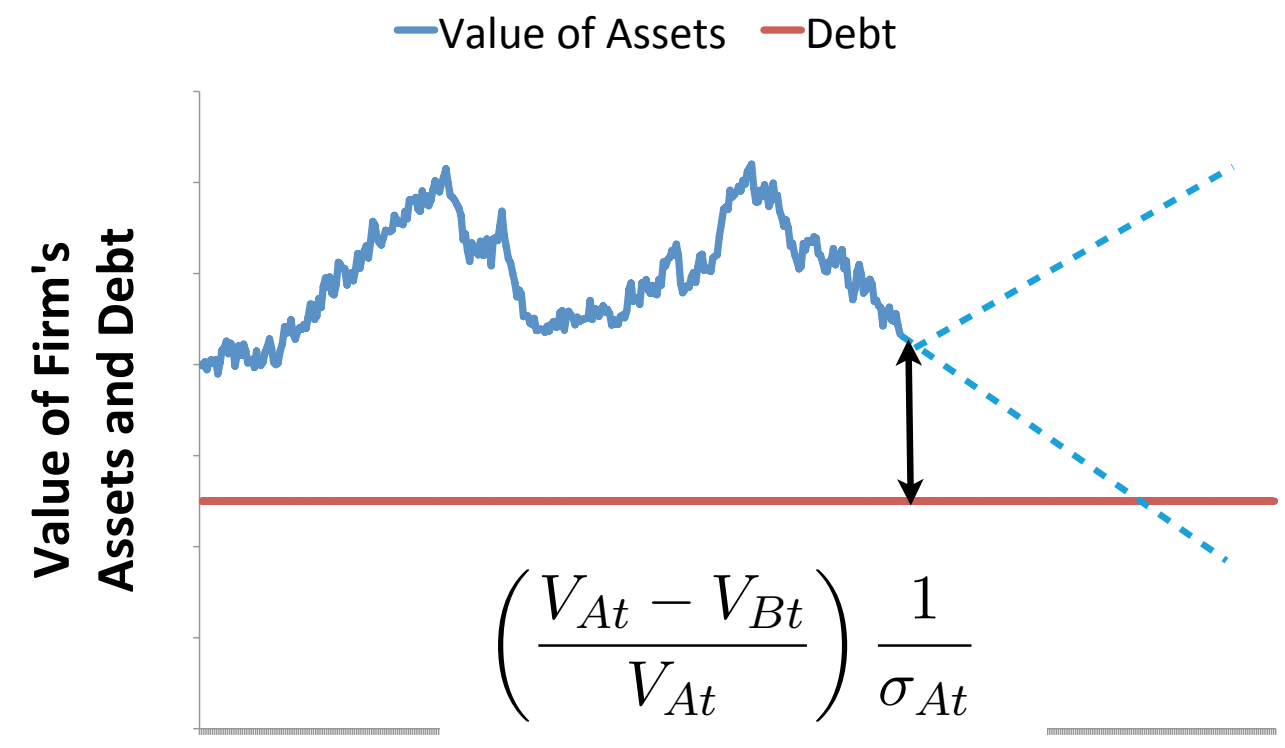

\section{Time}

Figure 1: The value of equity as a function of the value of assets.

$\left(\frac{V_{A}-V_{B}}{V_{A}}\right) \frac{1}{\sigma_{A}} \leq \frac{1}{\sigma_{E}}=\left(\frac{V_{A}-X}{V_{A}}\right) \frac{1}{\sigma_{A}} \leq\left(\frac{V_{A}-V_{A^{*}}}{V_{A}}\right) \frac{1}{\sigma_{A}}$

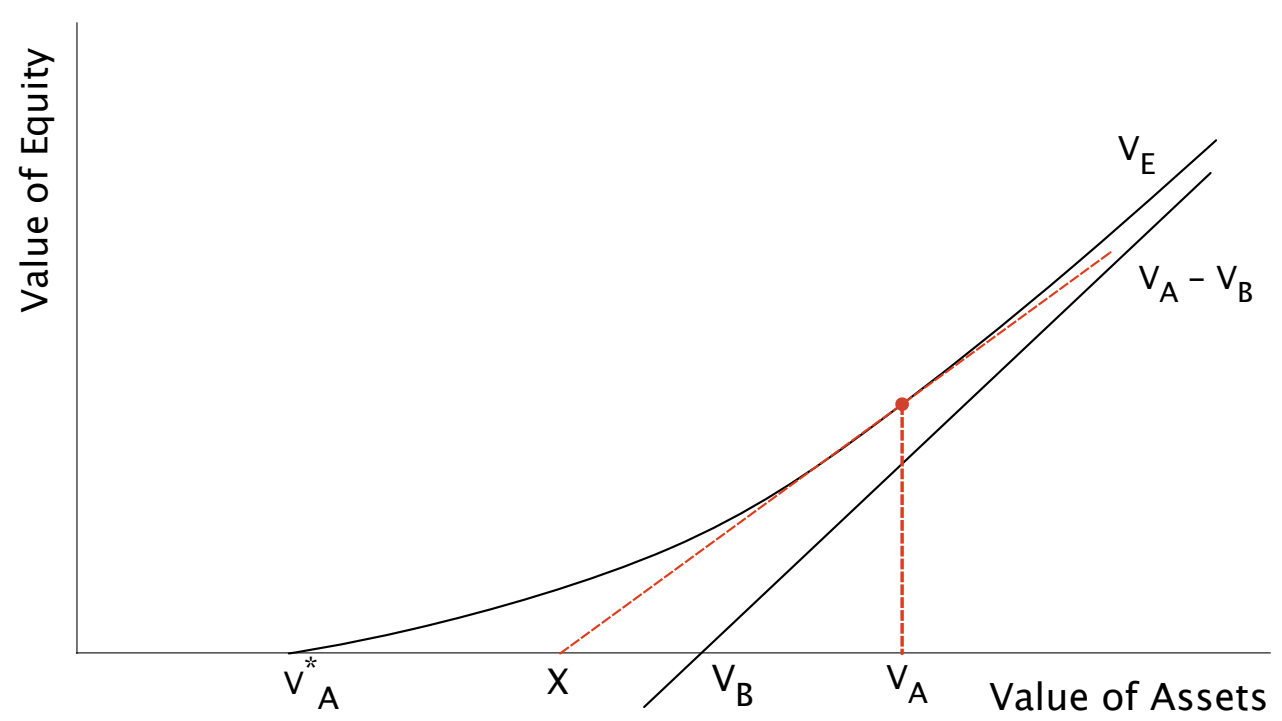

Figure 2: The value of equity as a function of the value of assets. 


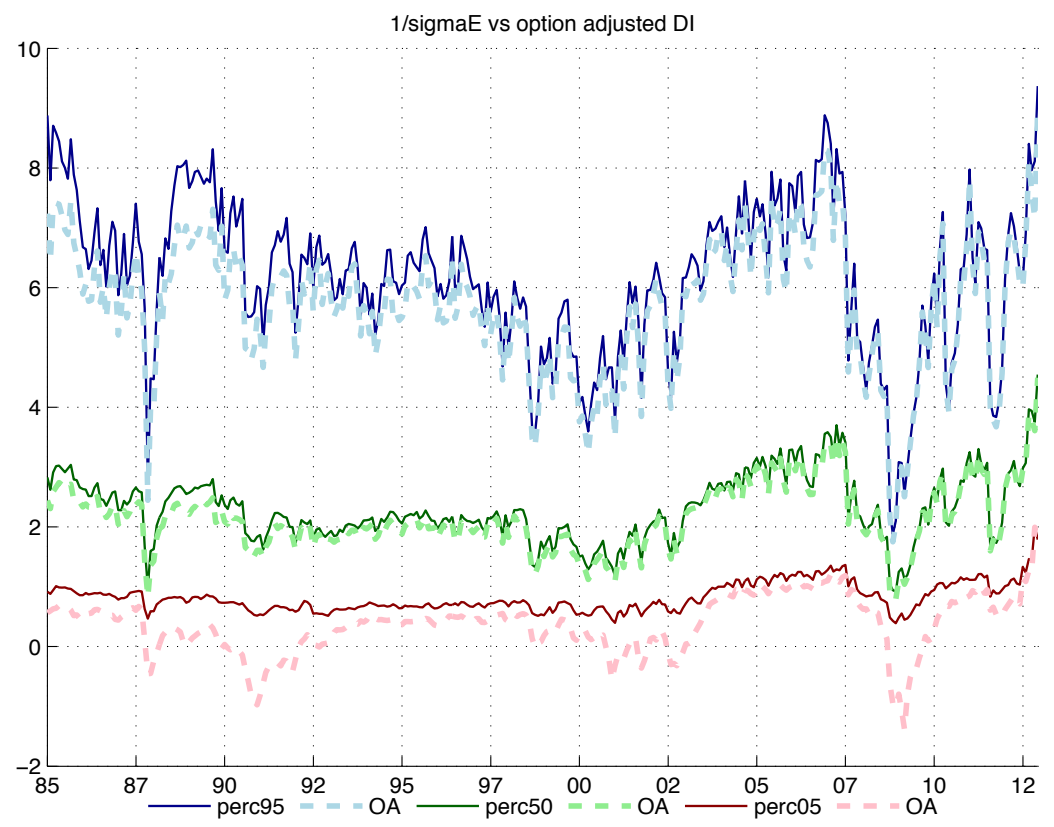

Figure 3: The 95th, 50th, and 05th percentiles of the distribution of $1 / \sigma_{E}$ (plain lines denoted by perc95, perc50 and perc05) and option-adjusted DI (dashed lines denoted "OA") estimated based on the Black and Scholes (1973)'s model. 


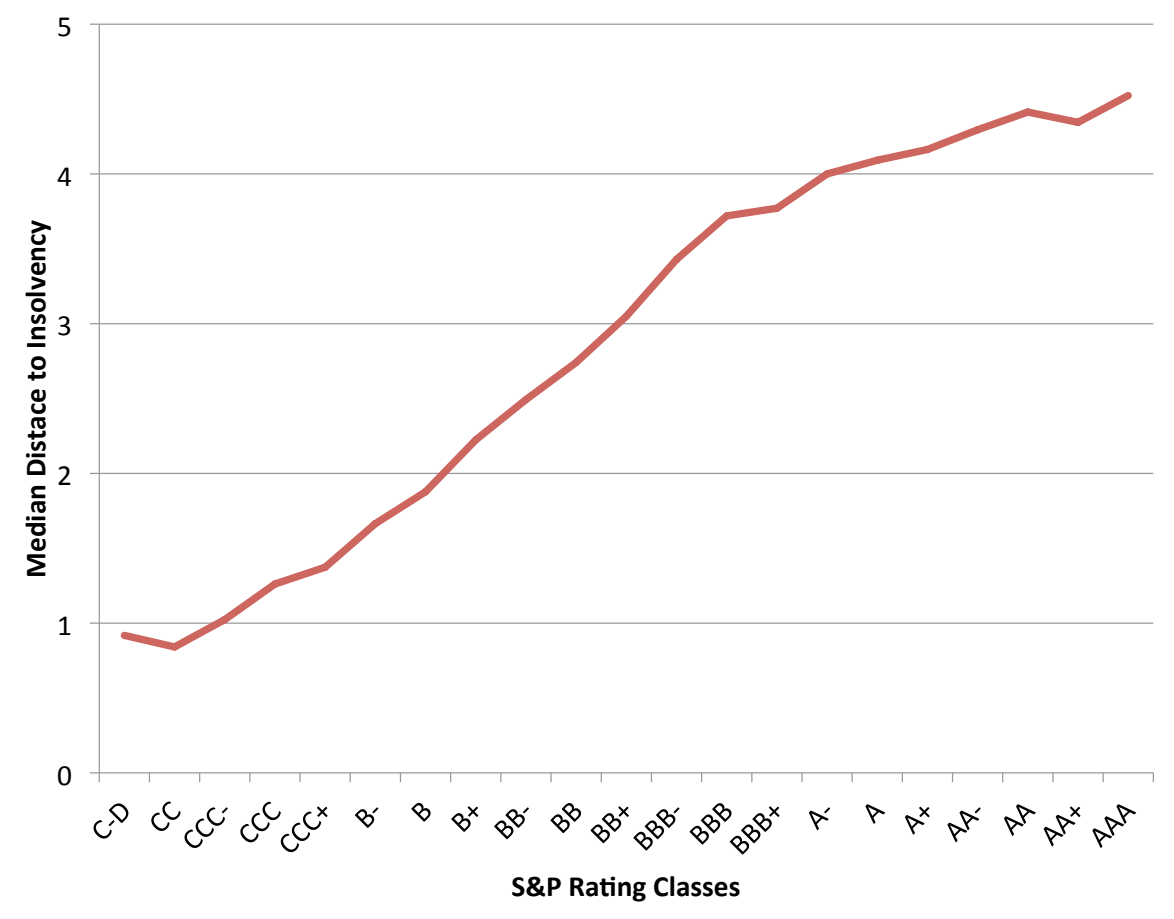

Figure 4: The empirical relationship between credit rating and measured DI.

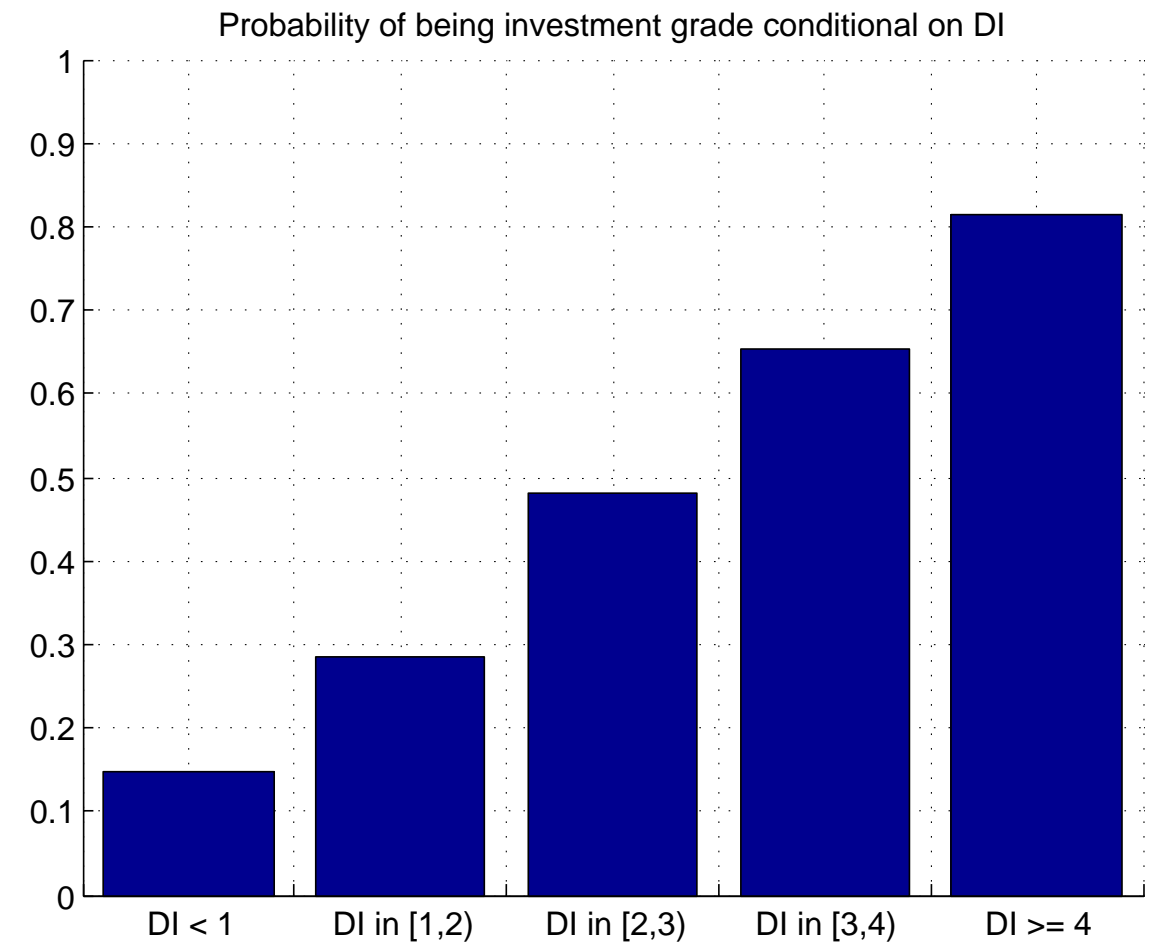

Figure 5: The empirical relationship between measured DI and credit rating. 


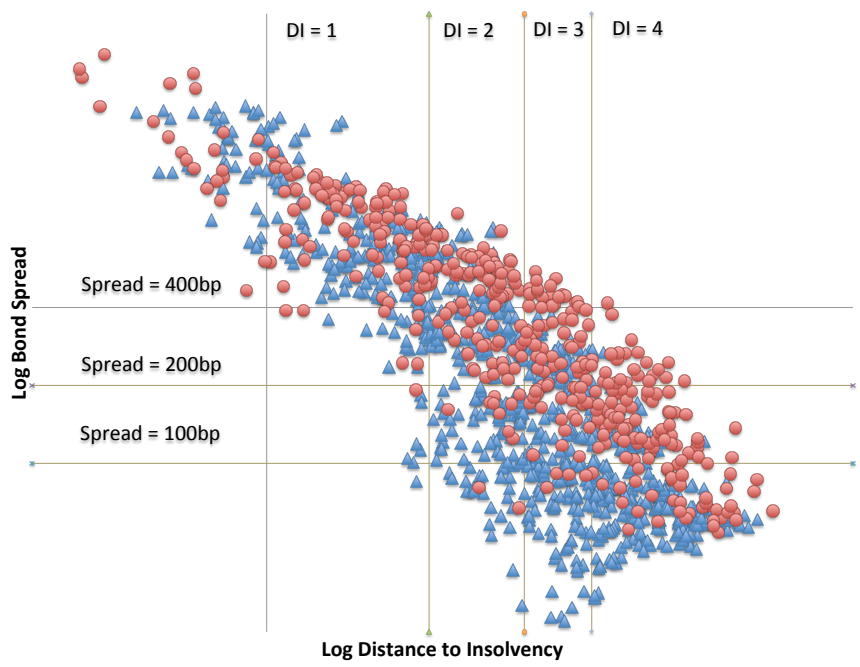

Figure 6: A scatter plot of monthly measured DI versus monthly averages of optionadjusted spreads for the Bank of America-Merrill Lynch corporate bond indices by ratings class for January 1997-December 2012, in log scale. Each point represents a single month and data for one of seven ratings from AAA to CCC and below. Pre-August 2007 data points are blue triangles, and post-August 2007 data points are red circles.

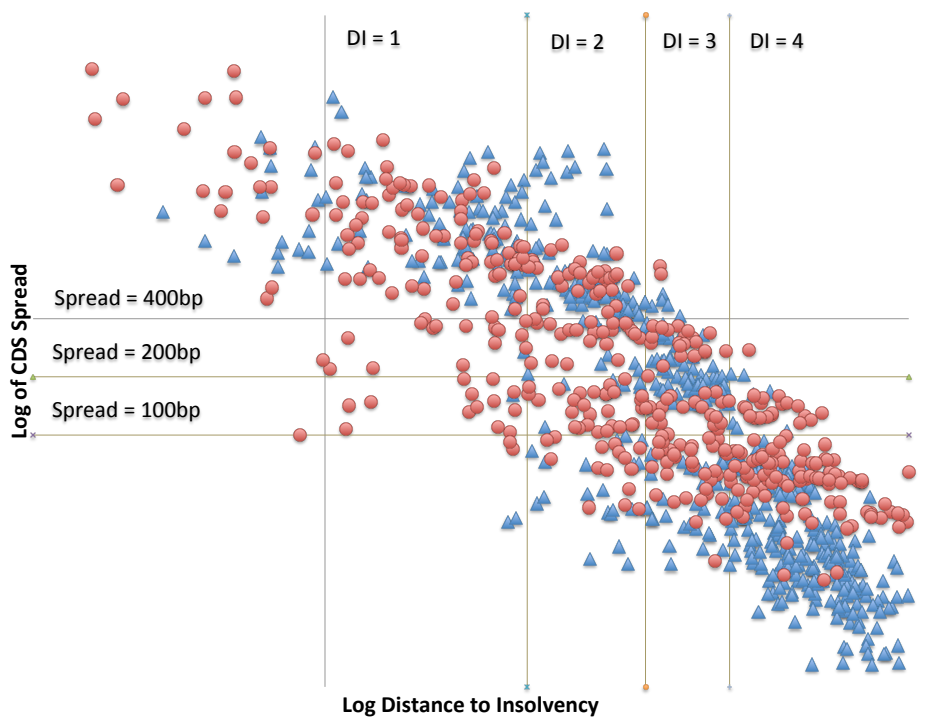

Figure 7: A scatter plot of monthly measured DI vs. monthly of averages of 5 year single name CDS rates for 2001-2011, in log scale. Data is pooled by credit rating. Each point represents a single month and one of seven ratings classes from AAA to CCC and below. Pre-August 2007 data points are blue triangles, and post-August 2007 data points are red circles. 


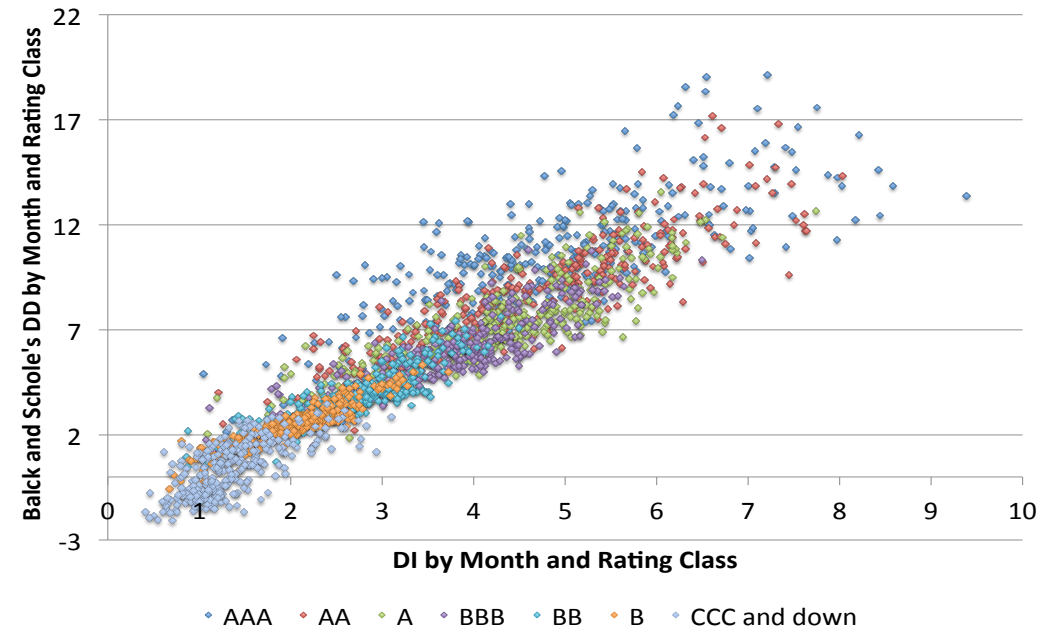

Figure 8: A scatter plot of monthly median measured DI versus monthly median Black and Scholes (1973)' Distance to Default by month and ratings class from December 1985 to December 2012. Each point represents a single month and data for one of seven ratings from AAA to CCC and below.

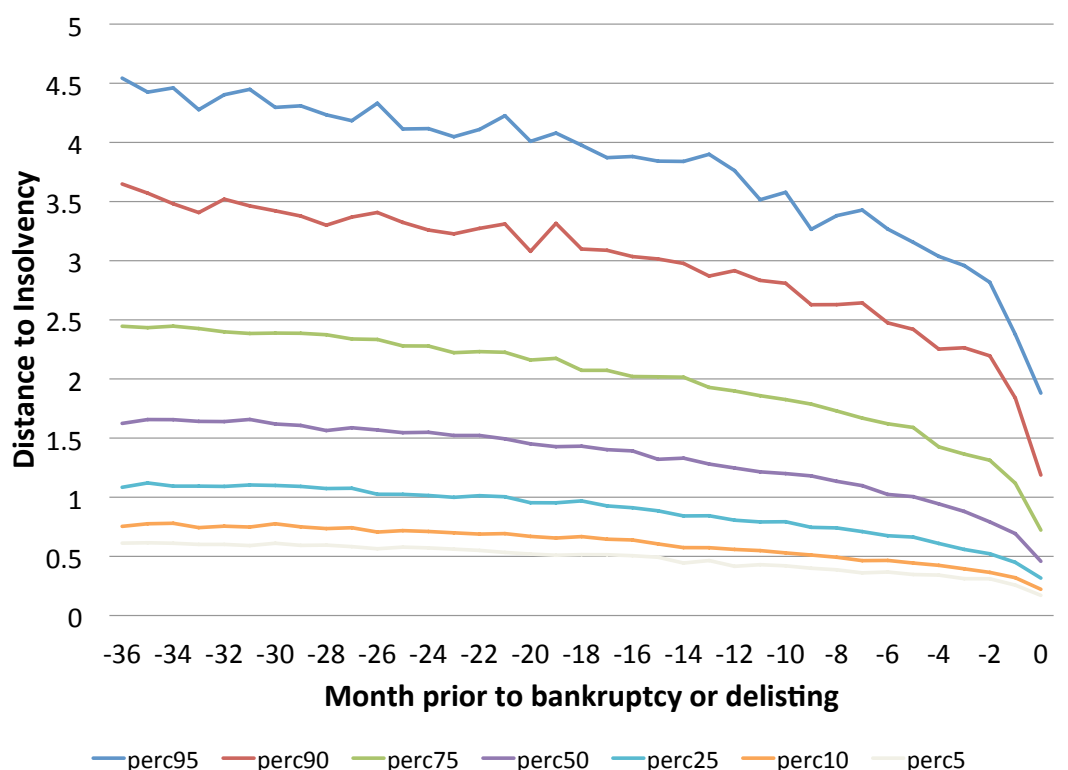

Figure 9: The distribution of measured DI for firms that declare bankruptcy in the 60 months prior to bankruptcy or delisting. 


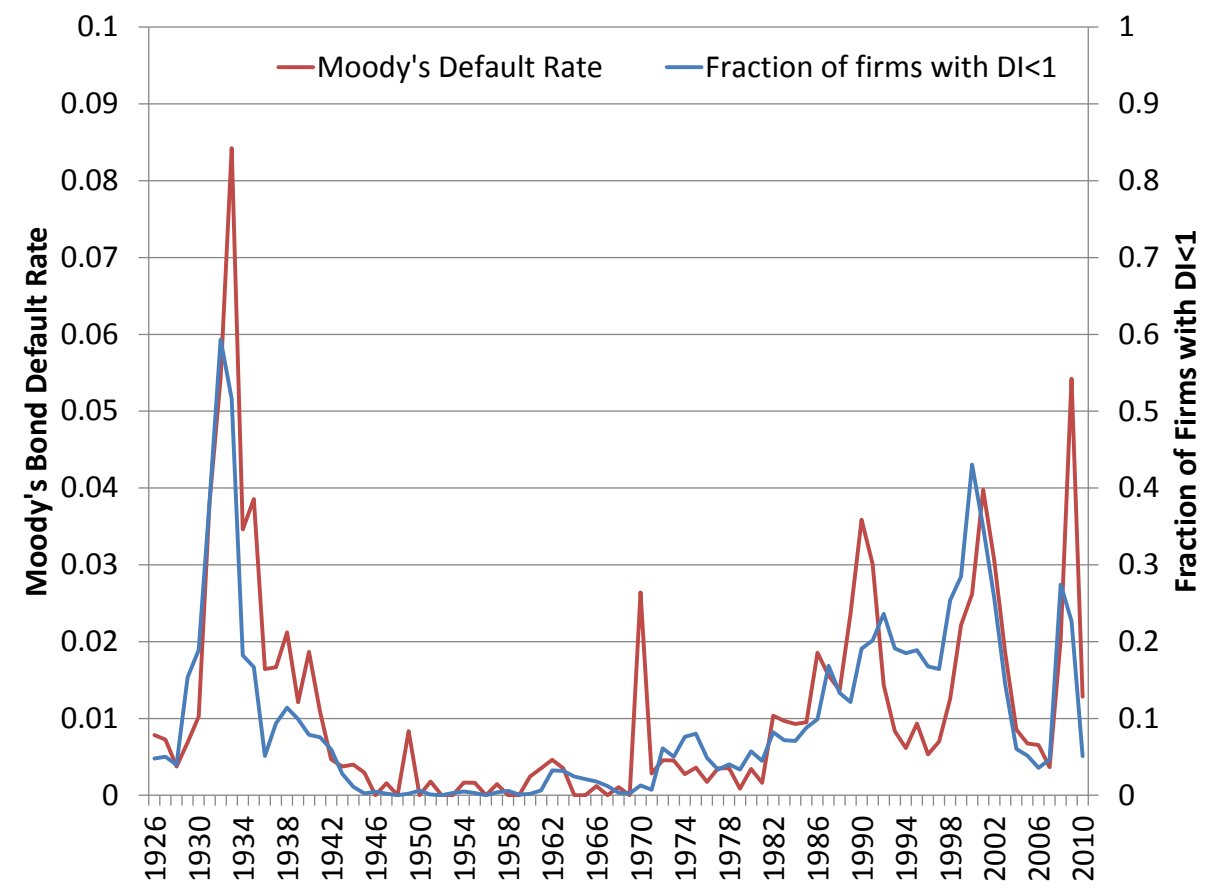

Figure 10: Annual DI versus annual issuer-weighted corporate default rates from Moody's Investor Service Annual Default Study 2012.

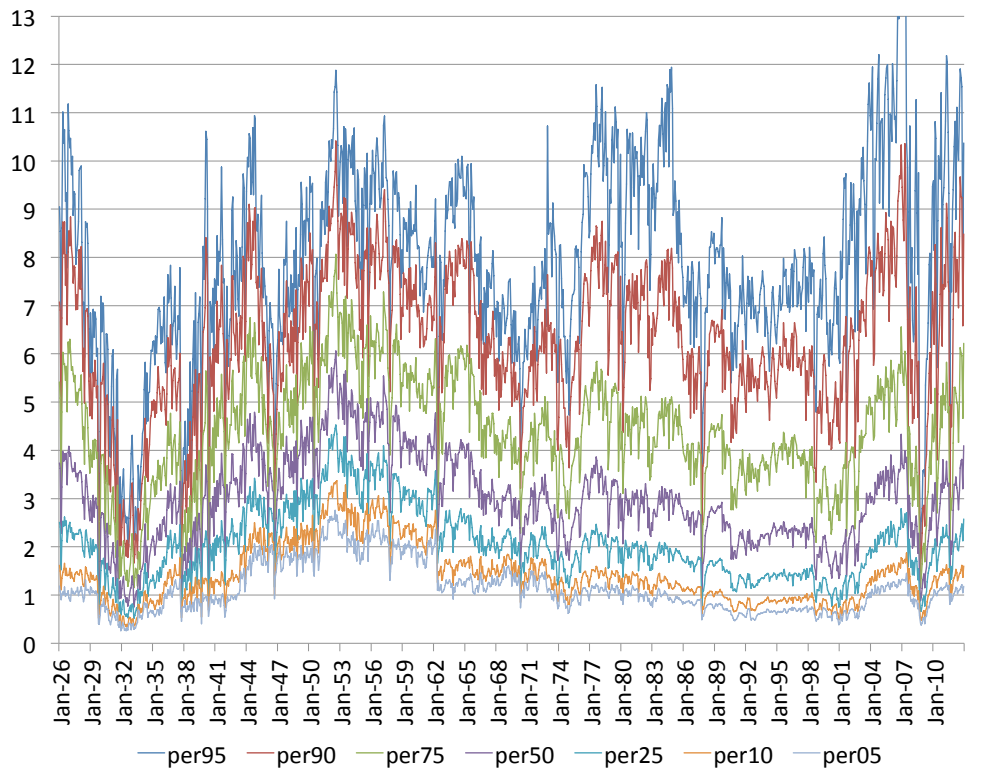

Figure 11: The distribution of DI, 1926-2012. 


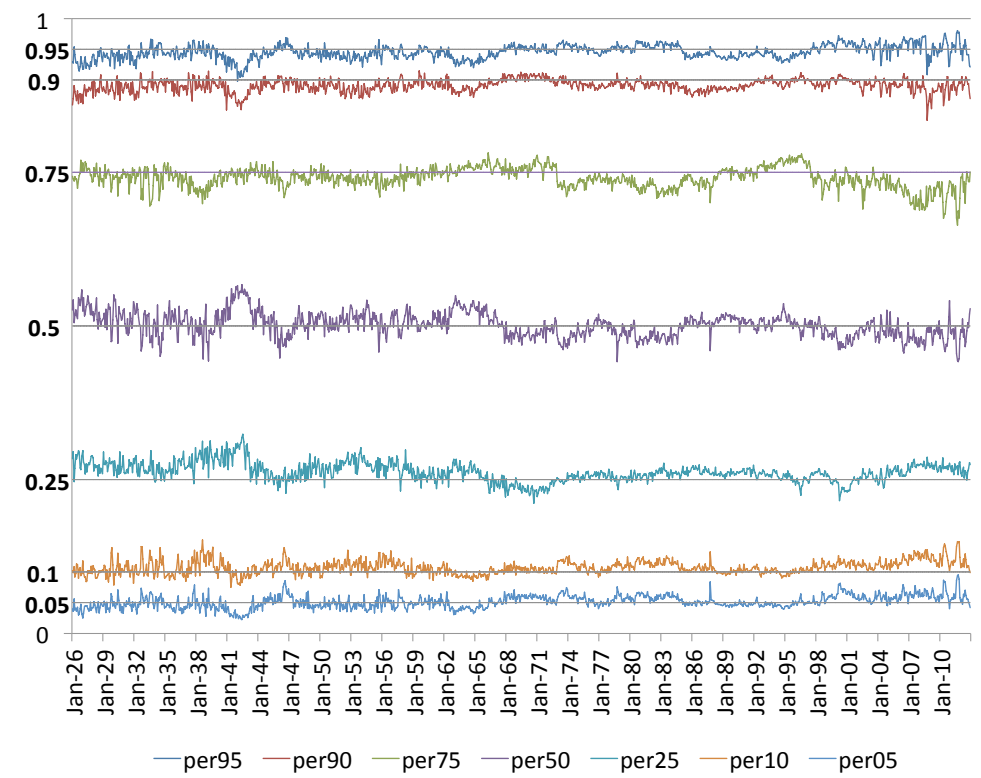

Figure 12: The $y$-axis plots the percentiles of a true lognormal distribution for $\frac{1}{\sigma_{E, t}}$ with the estimated cross-sectional mean and standard deviation for each month, 1926-2012. The colored lines display the empirical percentile cutoffs on each date.

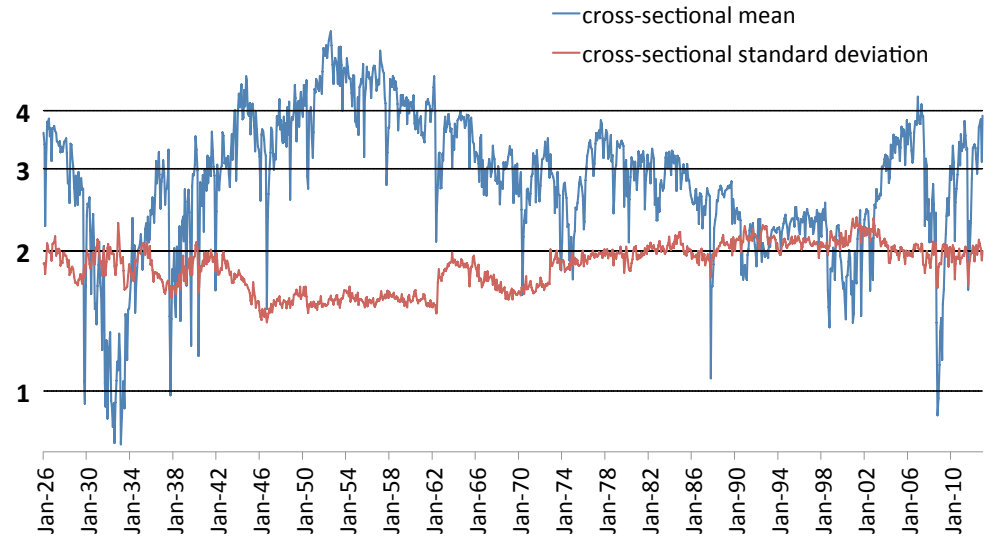

Figure 13: The mean and standard deviation of $\log$ DI, 1926-2012. The horizontal lines indicate the position of our benchmark cutoffs $(\mathrm{DI}=1,2,3,4)$ on the log scale. 


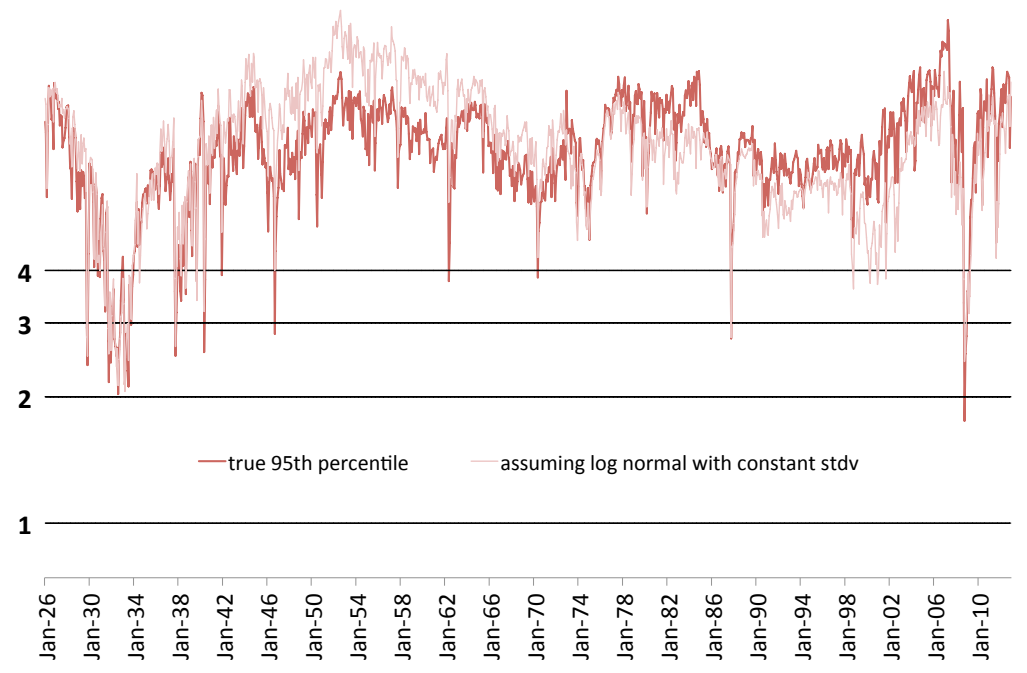

Figure 14: The 95th percentile of log DI 1926-2012 with time varying (red) versus constant (pink) standard deviation. The horizontal lines indicate the position of our benchmark cutoffs $(\mathrm{DI}=1,2,3,4)$ on the $\log$ scale.

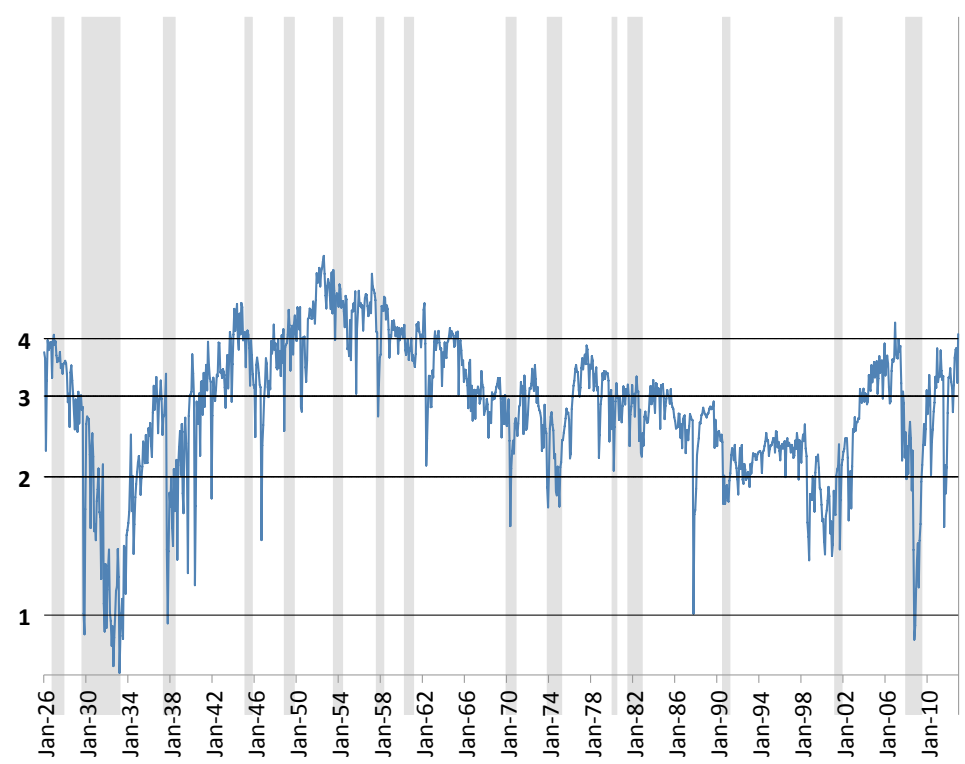

Figure 15: Deep and Broad Insolvency Crises: The log of the median of DI, 1926-2012. The horizontal lines indicate the position of our benchmark cutoffs $(\mathrm{DI}=1,2,3,4)$ on the log scale. Recessions are indicated by vertical gray bars. The 50th percentile DI hits 1 , associated with a highly vulnerable rating, in the Great Depression, 1937, 1987, and the Financial Crisis of 2008. 


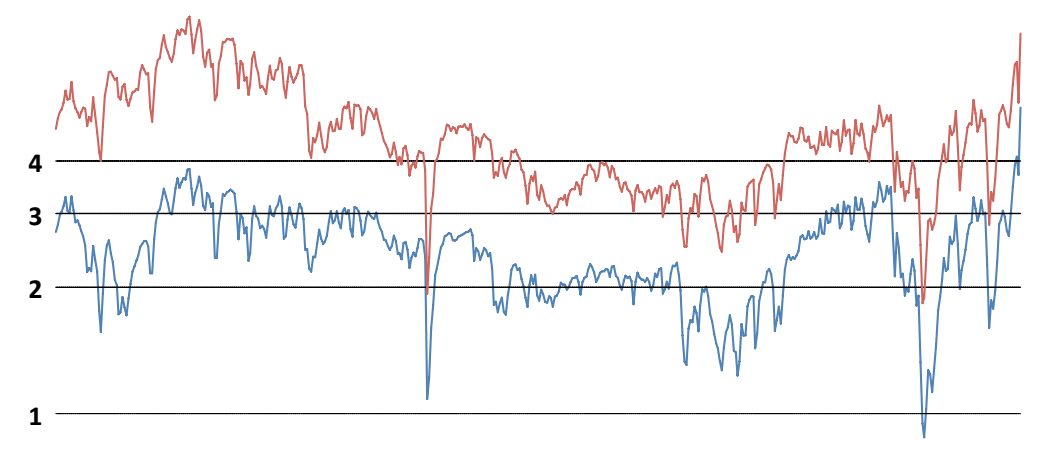

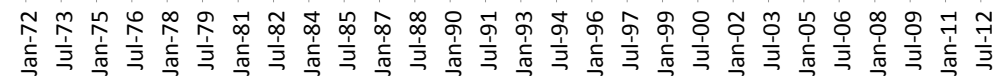

Figure 16: Leverage and asset volatility under the assumption of unlimited liability, 19712012. The horizontal lines indicate the position of our benchmark cutoffs ( $\mathrm{DI}=1,2,3,4)$ on the $\log$ scale.

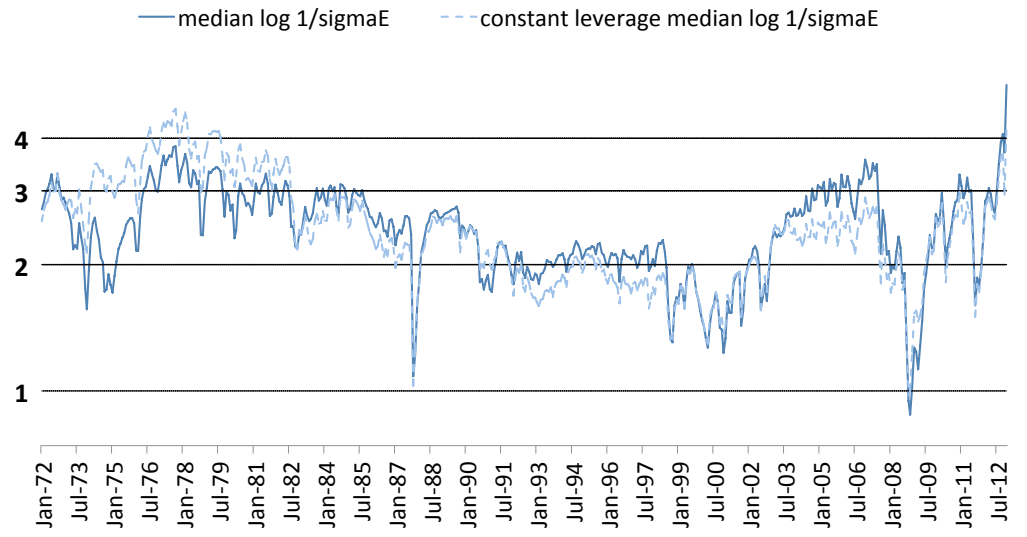

Figure 17: DI versus constant leverage DI, under the assumption of unlimited liability, 1971-2012. The horizontal lines indicate the position of our benchmark cutoffs $(\mathrm{DI}=1,2,3,4)$ on the $\log$ scale. 


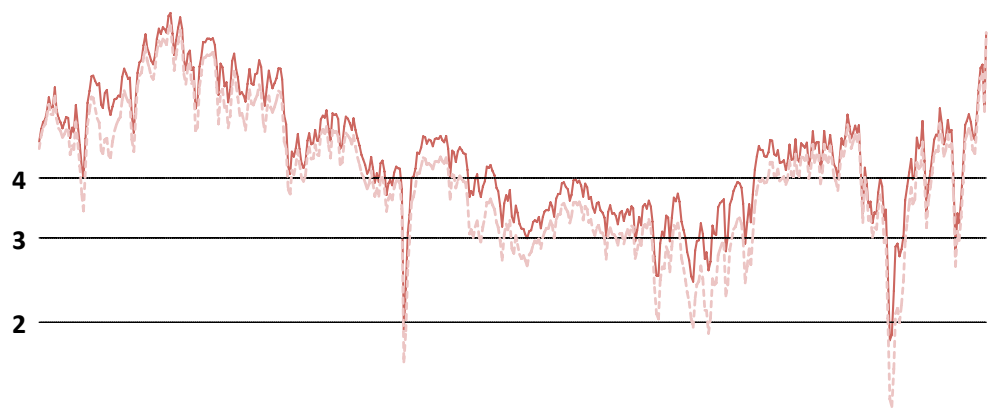

1

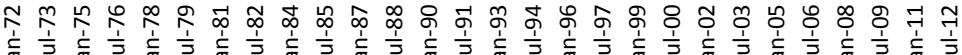

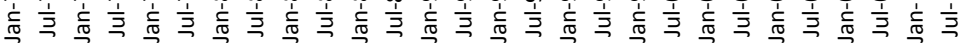

Figure 18: Asset volatility under the assumption of unlimited liability, and using Black and Scholes to compute the value of equity's default option, 1971-2012. In the calculation, we take $V_{B}$ be equal to total liabilities, as in the unlimited liability calculations. The horizontal lines indicate the position of our benchmark cutoffs $(\mathrm{DI}=1,2,3,4)$ on the log scale.

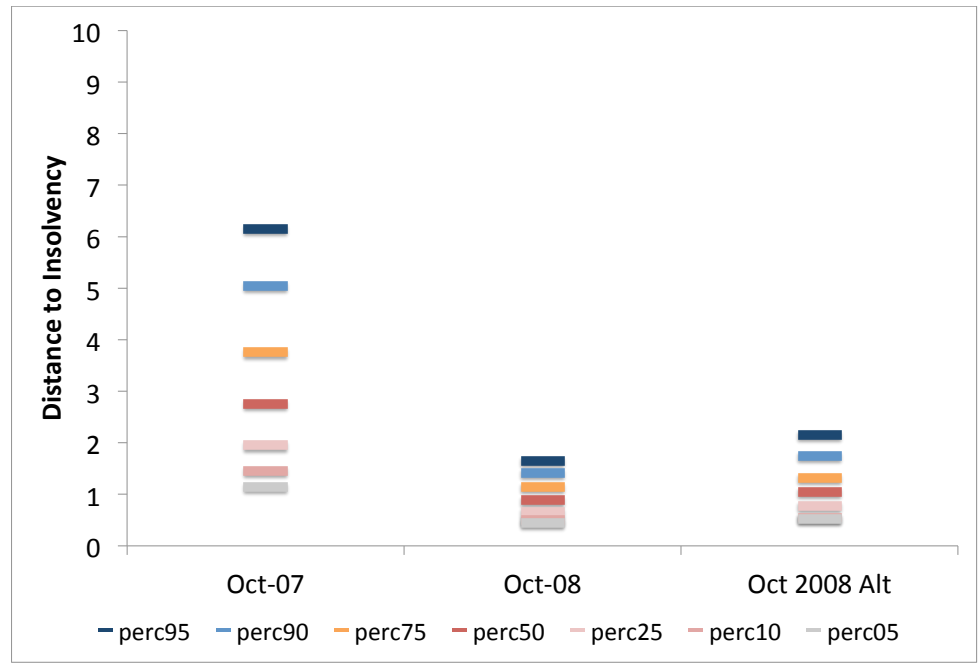

Figure 19: The percentiles of Distance to Insolvency for all firms in October 2007 and October 2008 together with the counterfactual alternative percentiles of Distance to Insolvency that would have arisen from October 2007 leverage and October 2008 asset volatility. 


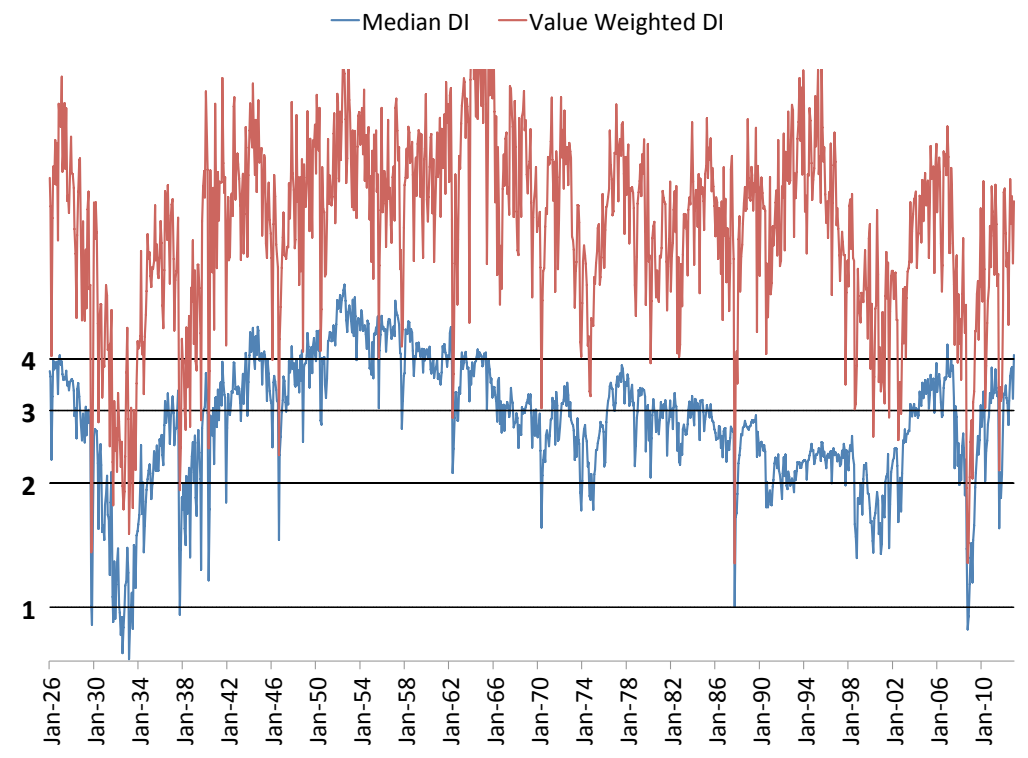

Figure 20: The DI for the CRSP value weighted portfolio and the DI of the median firm 1926-2012. The horizontal lines indicate the position of our benchmark cutoffs $(\mathrm{DI}=1,2,3,4)$ on the log scale.

-Non-Financials -Financials

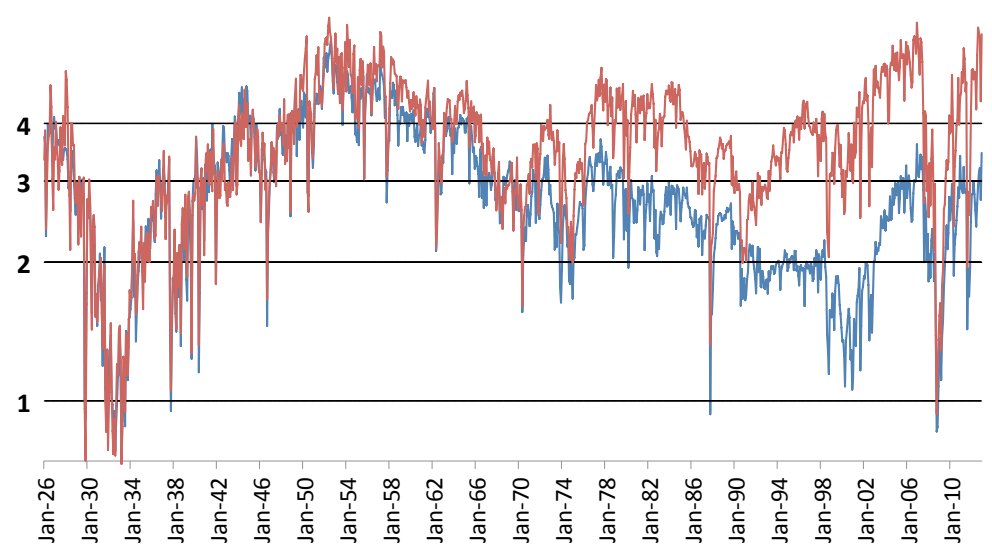

Figure 21: A comparison of the log median DI for financial and non-financial firms, 19262012. The horizontal lines indicate the position of our benchmark cutoffs ( $\mathrm{DI}=1,2,3,4)$ on the $\log$ scale. 


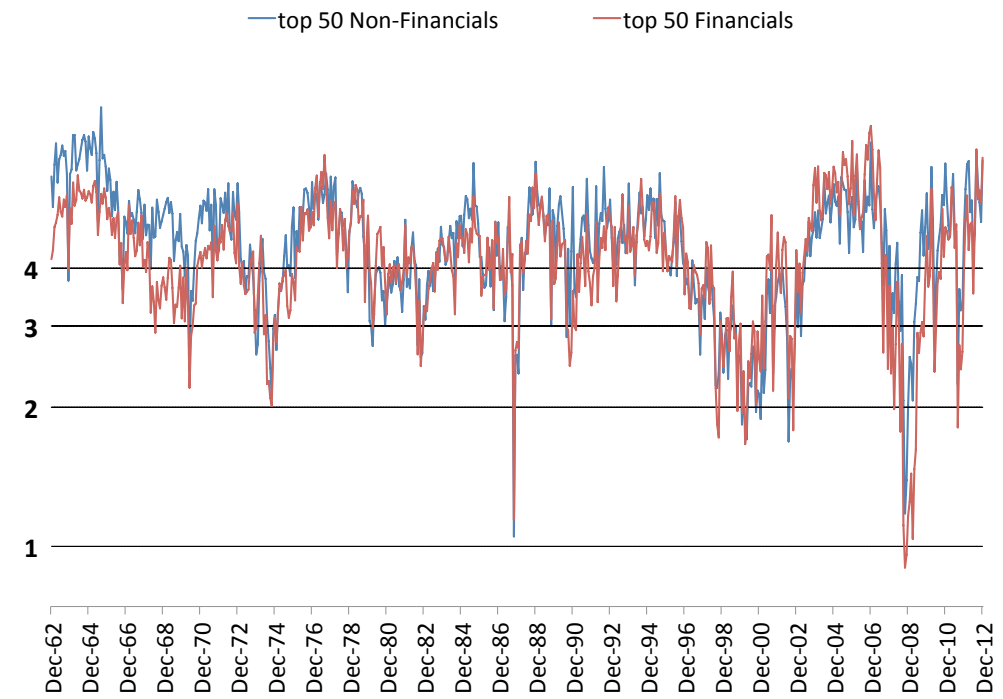

Figure 22: A comparison of the log median DI for the largest 50 financial and non-financial firms in terms of market capitalization, 1962-2012. The horizontal lines indicate the position of our benchmark cutoffs ( $\mathrm{DI}=1,2,3,4)$ on the log scale.

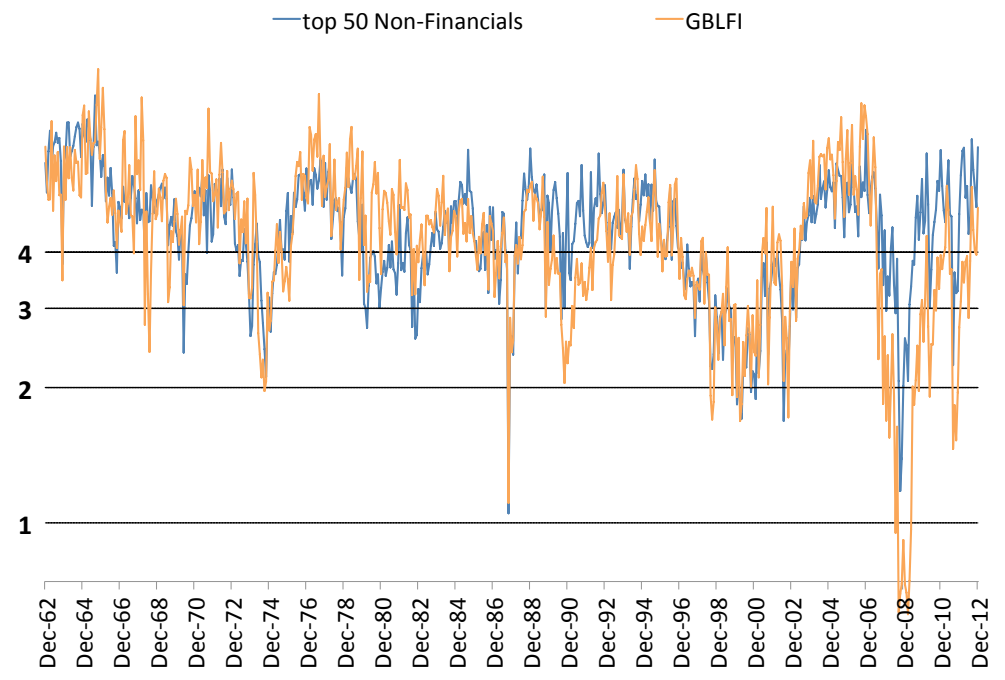

Figure 23: A comparison of the log median DI for the Government Backed Large Financial Institutions and the largest 50 non-financial firms in terms of market capitalization, 19622012. The horizontal lines indicate the position of our benchmark cutoffs ( $\mathrm{DI}=1,2,3,4)$ on the log scale. 


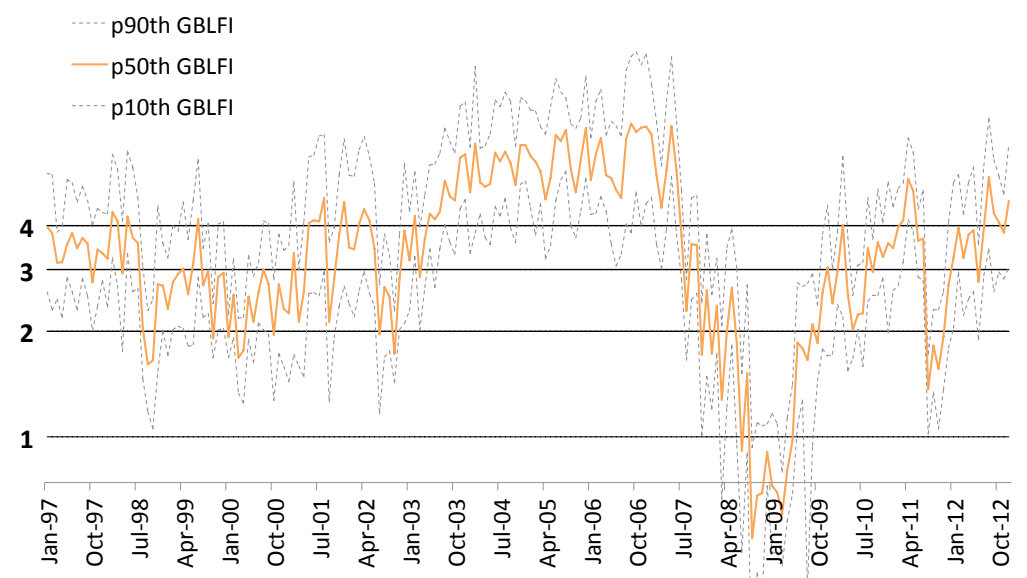

Figure 24: The 90th percentile, median, and 10th percentile of DI for the GBLFI's from 1997-2012. The horizontal lines indicate the position of our benchmark cutoffs ( $\mathrm{DI}=1,2,3,4)$ on the log scale.
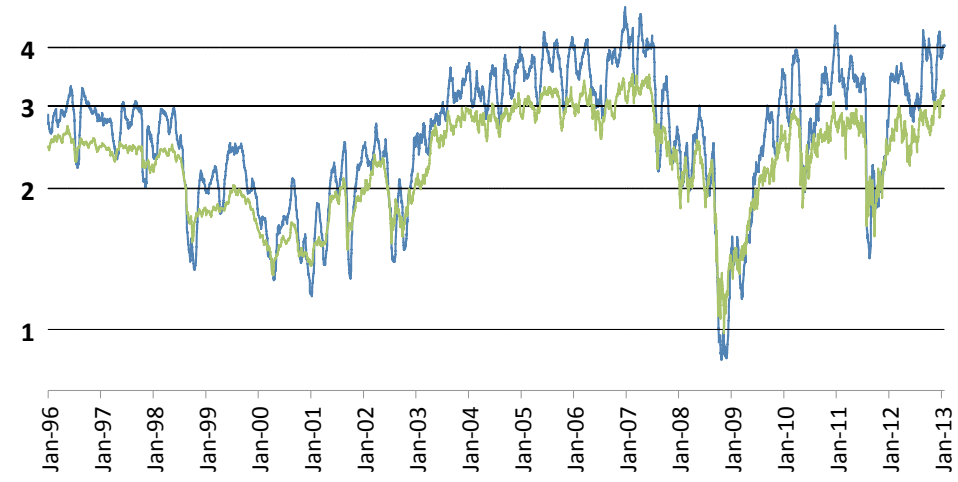

Figure 25: The mean of the log of inverse realized versus option implied volatilities, 19932012. The horizontal lines indicate the position of our benchmark cutoffs (DI=1,2,3,4) on the $\log$ scale. 
Table 1: Government Backed Large Financial Institutions

\begin{tabular}{lll}
\hline \hline Name & & Sample \\
\hline American Express & Amex & $01 / 02 / 1969$ to today \\
American Insurance Group (AIG) & AIG & $12 / 14 / 1972$ to today \\
Bank of America & BOA & $01 / 02 / 1969$ to today \\
Bank of New York & BONY & $12 / 04 / 1969$ to today \\
Branch Banking and Trust & BB\&T & $12 / 14 / 1972$ to today \\
Bear Stearns & BST & $10 / 29 / 1985$ to $05 / 30 / 2008$ \\
Capital One & COF & $11 / 16 / 1994$ to today \\
City & C & $12 / 31 / 1925$ to today \\
Fifth Third Bancorp & FITB & $04 / 23 / 1975$ to today \\
Fannie Mae & FNMA & $08 / 31 / 1970$ to $07 / 07 / 2010$ \\
Freddy Mac & FRE & $08 / 10 / 1989$ to $07 / 07 / 2010$ \\
Goldman Sachs & GS & $05 / 04 / 1999$ to today \\
JP Morgan & JPM & $03 / 05 / 1969$ to today \\
Key Banks & KEY & $02 / 23 / 1972$ to today \\
Lehman Brothers & LEH & $05 / 31 / 1994$ to $09 / 17 / 2008$ \\
Merrill Lynch & MERRILL & $07 / 27 / 1971$ to $12 / 31 / 2008$ \\
MetLife & MET & $04 / 05 / 2000$ to today \\
Morgan Stanley & MS & $03 / 21 / 1986$ to today \\
PNC Financial Services & PNC & $12 / 14 / 1972$ to today \\
Regions Financial Corp & REG FIN & $12 / 14 / 1972$ to today \\
Suntrust Banks & SUNTRUST & $07 / 01 / 1985$ to today \\
State Street Boston Corporation & STATESTREET & $12 / 14 / 1972$ to today \\
US Bancorps & USB & $12 / 14 / 1972$ to today \\
Wachovia Corporation & WACH & $12 / 14 / 1972$ to $12 / 31 / 2008$ \\
Washington Mutual & WaMu & $03 / 11 / 1983$ to 09/26/2008 \\
\hline & & \\
\hline
\end{tabular}




\section{References}

Anat Admati, Peter DeMarzo, Martin Hellwig, and Paul Pfleiderer. Debt overhang and capital regulation. March 2012. 5

Heitor Almeida and Thomas Philippon. The risk-adjusted cost of financial distress. The Journal of Finance, 62:2557-2586, 2007. 6

Cristina Arellano, Yan Bai, and Patrick Kehoe. Financial markets and fluctuations in uncertainty. Working paper, March 2011. 3

Ben Bernanke. Nonmonetary effects of the financial crisis in the propagation of the great depression. The American Economic Review, 73(3):257-276, 1983. 4

Ben Bernanke and Mark Gertler. Agency costs, net worth, and business fluctuations. The American Economic Review, 1:14-31, 1989. 1

Ben Bernanke, Mark Gertler, and Simon Gilchrist. The financial accelerator in a quantitative business cycle framework. In John Taylor and Michael Woodford, editors, Handbook of Macroeconomics, chapter 21, pages 1341-1392. Elsevier, 1999. 1

Harjoat S. Bhamra, Lars-Alexander Kuehn, and Ilya A. Strebulaev. The aggregate dynamics of capital structure and macroeconomic risk. The Review of Financial Studies, $23: 1-55,2010.6$

Sreedhar Bharath and Tyler Shumway. Forecasting default with the merton distance to default model. Review of Financial Studies, 21(3):1339-1369, May 2008. 16

Fischer Black and John C. Cox. Valuing corporate securities: Some effects of bond indenture provisions. Journal of Finance, 31(2):351-367, May 1976. 6

Fischer Black and Myron Scholes. The pricing of options and corporate liabilities. Journal of Political Economy, 81:637-654, 1973. 11, 12, 15, 16, 20, 21, 27, 28, 29, 31, 34, 39

Nicholas Bloom. The impact of uncertainty shocks. Econometrica, 77(3):623-685, May 2009. 3

Phillip Bond, Itay Goldstein, and Edward S. Prescott. Market based corrective actions. Review of Financial Studies, 23:781-820, 2010. 23

John Y. Campbell, Martin Lettau, Burton G. Malkiel, and Yexiao Xu. Have individual stocks become more volatile? an empirical exploration of idiosyncratic risk. The Journal of Finance, 56:1-43, 2001. 22

Charles T. Carlstrom and Timothy S. Fuerst. Agency costs, net worth, and business fluctuations: A computable general equilibrium analysis. The American Economic Review, 87:893-910, 1997. 1

Sudheer Chava and Robert A. Jarrow. Bankruptcy prediction with industry effects. Review of Finance, 8(4):537-569, 2004. 16 
Hui Chen. Macroeconomic conditions and the puzzles of credit spreads and capital structure. The Journal of Finance, 65:2171-2212, 2010. 6, 11

Jaewon Choi and Matthew Richardson. The volatility of the firm's assets. Working Paper, 2013. 3

Lawrence Christiano, Roberto Motto, and Massimo Rostagno. Financial factors in economic fluctuations. Working paper, May 2010. 3

Thomas Cooley and Vincenzo Quadrini. Financial markets and firm dynamics. The American Economic Review, 91(5):1286-1310, 2001. 1

Thomas Cooley, Ramon Marimon, and Vincenzo Quadrini. Aggregate consequences of limited contract enforceability. Journal of Political Economy, 112(4):817-847, 2004. 1

Douglas Diamond and Zhiguo He. A theory of debt maturity: The long and short of debt overhang. The Journal of Finance, forthcoming. 6

Douglas Diamond and Rachuram Rajan. Fear of fire sales, illiquidity seeking, and credit freezes, 2011. 5

Darrell Duffie. Measuring Corporate Default Risk. Oxford University Press, 2011. 1, 6, $8,16,27$

Darrell Duffie, Leandro Saita, and Ke Wang. Multi-period corporate default prediction with stochastic covariates. Journal of Financial Economics, 83:635-665, 2007. 16

Darrell Duffie, Andreas Eckner, Guillaume Horel, and Leandro Saita. Frailty correlated default. Journal of Finance, 64(5):2089-2123, October 2009. 16

Mark Gertler and Nobuhiro Kiyotaki. Financial intermediation and credit policy in business cycle analysis. In Handbook of Monetary Economics, volume 3, chapter 11, pages 547-599. Elsevier, 2010. 4

Ronald Giammarino, Eduardo Schwartz, and Josef Zechner. Market valuation of bank assets and deposit insurance and canada. The Canadian Journal of Economics, 22(1): 109-127, February 1989. 23

Kay Giesecke, Francis A. Longstaff, Stephen Schaefer, and Ilya Strebulaev. Corporate default risk: A 150 year perspective. Journal of Financial Economics, 102:233-250, 2011. 3

Simon Gilchrist and Egon Zakrajsek. Credit spreads and business cycle fluctuations. American Economic Review, 2012:1692-1720, 2012. 28

Simon Gilchrist, Jae W. Sim, and Egon Zakrajsek. Uncertainty, financial frictions, and investment dynamics. Working paper, 2010. 3

Dirk Hackbarth, Jianjun Miao, and Erwan Morellec. Capital structure, credit risk and macroeconomic conditions. Journal of Financial Economics, 82:519-550, 2006. 11 
Kyle Jurado, Sydney C. Ludvigson, and Serena Ng. Measuring uncertainty. 2013. 3

Brian Kelly, Hanno Lustig, and Stijn Van Nieuwerburgh. Too-systemic-to-fail: What option markets imply about sector-wide government guarantees. Working paper, Chicago Booth, UCLA, Anderson and NYU Stern, 2013a. 23

Bryan T. Kelly, Hanno Lustig, and Stijn Van Nieuwerburgh. Firm volatility in granular networks. 2013b. 2

Charles P. Kindleberger and Robert Aliber. Manias, Panics, and Crashes: A History of Financial Crises. Number 39 in Wiley Investment Classics. John Wiley and Sons, fifth edition, 2005. 3

Nobuhiro Kiyotaki and John Moore. Credit cycles. Journal of Political Economy, 105: 211-248, 1997. 1

Hayne E. Leland. Corporate debt value, bond covenants, and optimal capital structure. Journal of Finance, 49(4):1213-1252, September 1994. 1, 6, 8, 9, 10, 11, 26

Francis Longstaff and Eduardo Schwartz. A simple approach to valuing risky fixed and floating rate debt. Journal of Finance, 50(3):789-819, July 1995. 6

Hanno Lustig and Priyank Gandhi. Size anomalies in bank stock returns. The Journal of Finance, forthcoming. 23

Robert C. Merton. On the pricing of corporate debt: The risk structure of interest rates. Journal of Finance, 29(2):449-470, May 1974. 1, 6, 8, 9, 11, 29

Franco Modigliani and Merton H. Miller. The cost of capital, corporate finance and the theory of investment. American Economic Review, 48:262-97, 1958. 6

Moody's. Annual default study: Corporate default and recovery rates, 1920-2011. Credit Policy, 2012. 17

Stuart C. Myers. Determinants of corporate borrowing. Journal of Financial Economics, 5:147-175, 1977. 6

Adriano Rampini and S. Viswanathan. Collateral, risk management, and the distribution of debt capacity. Journal of Finance, 65(6):2293-2322, December 2010. 3

Carmen Reinhart and Kenneth Rogoff. This Time Is Different: Eight Centuries of Financial Folly. Princeton University Press, 2009. 3, 4

Zhao Sun, David Munves, and David Hamilton. Public firm expected default frequency (edf) credit measures: Methodology, performance, and model extensions. Moody's Analytics Modeling Methodology, June 2012. 1, 6, 16

Robert Townsend. Optimal contracts and competitive markets with costly state verification. Journal of Economic Theory, 22:265-293, 1979. 6 
Maria Vassalou and Yuhang Xing. Default risk in equity returns. Journal of Finance, 59: 831-868, 2004. 27

Anne P. Villamil. Modigliani-miller theorem. In The New Palgrave Dictionary of Economics, Second Edition. Eds. Steven N. Durlauf and Lawrence E. Blume. Palgrave Macmillan, 2008. 6 